\title{
Exchange rate pass-through to import prices in Europe: a panel cointegration approach
}

\author{
Antonia Arsova ${ }^{1,2}$ \\ Received: 2 February 2019 / Accepted: 14 March 2020 / Published online: 10 April 2020 \\ (c) The Author(s) 2020
}

\begin{abstract}
This paper takes a panel cointegration approach to the estimation of short- and longrun exchange rate pass-through (ERPT) to import prices in the European countries. Although economic theory suggests a long-run relationship between import prices and exchange rate, in recent empirical studies its existence has either been overlooked or it has proven difficult to establish. Resorting to novel tests for panel cointegration, we find support for the equilibrium relationship hypothesis. Exchange rate pass-through elasticities, estimated by two different techniques for cointegrated panel regressions, give insight into the most recent development of the ERPT.
\end{abstract}

Keywords Exchange rate pass-through · Import prices · Panel cointegration · Cross-sectional dependence $\cdot$ Common factors

JEL Classification C12 $\cdot$ C23 $\cdot$ F31

\section{Introduction}

Exchange rate pass-through (ERPT) to import prices measures the extent to which import prices, expressed in the currency of the importing country, reflect changes in the exchange rate with its trading partners. Assuming that export prices are determined by a markup over marginal costs, the import price elasticity with respect to the exchange rate depends on the exporters' pricing strategies. If exporters choose to

The author is grateful to Boris Blagov and to the participants at the 25th International Panel Data Conference in Vilnius, Lithuania, for helpful discussions and to two anonymous referees and the Associate Editor for their constructive comments and suggestions.

$凶$ Antonia Arsova

arsova@statistik.tu-dortmund.de; antonia.arsova@rwi-essen.de

1 Faculty of Statistics, TU Dortmund University, Vogelpothsweg 78, 44227 Dortmund, Germany

2 RWI - Leibniz Institute for Economic Research, Hohenzollernstraße 1-3, 45128 Essen, Germany 
absorb exchange rate fluctuations into their markup, a strategy also known as local currency pricing (LCP) or pricing-to-market, then import prices remain largely unaffected by exchange rate shocks and the ERPT is said to be incomplete. On the other hand, if exporters choose not to adjust their markup, exchange rate fluctuations get reflected in full into import prices, which is known as producer currency pricing (PCP). The ERPT in this case is said to be complete. Under complete ERPT, depreciation of the importing country's currency translates into increase of import prices and, if transmitted further to consumer prices, may lead to inflation. In general, two stages of ERPT can be distinguished along the pricing chain: ERPT into import prices (first-stage pass-through) and subsequently into consumer prices (second-stage pass-through).

Understanding the degree and the determinants of the different stages of ERPT is important for several economic policy issues. From the standpoint of monetary policy makers, the speed and the extent by which ERPT affects consumer price inflation is essential for assessment of monetary policy transmission, as well as for forecasting inflation. Low second-stage pass-through is thus crucial for a monetary authority looking to stabilize inflation. On the other hand, the responsiveness of import prices to exchange rate changes directly affects domestic demand for imported goods and services, thus representing a channel through which current account imbalances can be adjusted. From this point of view, a higher first-stage pass-through is desirable.

The vast literature on ERPT can be broadly divided into two strands, depending on whether it focuses on the micro- or macroeconomic aspects of the ERPT phenomenon. The micro-level strand has its foundations in the industrial organization literature and links ERPT to market structure and the pricing behaviour of foreign firms, using disaggregated data for different products or industries. In contrast, the macro-level strand employs aggregated price measures and focuses on the role of macroeconomic factors as determinants of ERPT, yielding results most relevant for monetary policy issues. This paper falls into the second category, examining the ERPT to import prices through the prism of panel cointegration.

In the ever-growing body of empirical macro-studies on ERPT, one issue becomes apparent-namely, whether there exists a long-run equilibrium relationship between import prices, nominal exchange rate and other potential macroeconomic determinants of import prices. For example, Campa and Goldberg (2005) and Ben Cheikh and Rault (2016, 2017) find no or only weak evidence of cointegration and proceed to estimate an ERPT equation in first differences. De Bandt and Razafindrabe (2014) do not even consider the possibility of cointegrating relations and having established the nonstationarity of the model variables proceed to estimate a model in first differences as well. De Bandt et al. (2008), Brun-Aguerre et al. (2012) and Ben Cheikh and Cheik (2013) do establish a cointegrating relation and thus estimate error-correction (EC) models for the ERPT. However, De Bandt et al. (2008) allow for level shifts and structural breaks in the cointegrating relation, while Brun-Aguerre et al. (2012) employ individual-unit and first-generation panel cointegration tests, the results of which might be compromised by unattended cross-sectional dependence. Recognizing the importance of cross-sectional dependence, Ben Cheikh and Cheik (2013) apply the second-generation tests of Westerlund (2007) and convincingly reject the null of 
no cointegration in the ERPT equation for a panel of 27 OECD countries. ${ }^{1}$ Delatte and López-Villavicencio (2012) and Brun-Aguerre et al. (2017) also find strong evidence for cointegration, but they focus on asymmetric ERPT - that is, allowing the effects of exchange rate appreciation or depreciation on import prices to differ. Consequently, they argue that imposing the restriction of symmetric ERPT may hinder revealing the long-run equilibrium. The evidence on the existence of a linear cointegration relationship is, therefore, inconclusive.

The presence or absence of cointegration determines the choice of estimation methodology and models which do not consider it have been criticized on two grounds. First, ignoring a significant error-correction (EC) term leads to omitting essential information and hence to inferior model performance (Brun-Aguerre et al. 2012). Second, by evading the notion of cointegration as long-run equilibrium, other ad-hoc measures of long-run ERPT need to be constructed, whose estimates strongly depend on the choice of other model parameters, e.g. the lag order, and can thus become unreliable (De Bandt et al. 2008). Therefore, the debate on whether cointegration underlies the ERPT not only constitutes an interesting econometric puzzle, but has far-reaching consequences concerning the estimation results.

The contribution of this paper is twofold. First, employing novel second-generation panel cointegration tests it provides evidence on the existence of a long-run equilibrium relationship between the import prices and their determinants, including the nominal exchange rate, for a panel of nineteen European countries. Contrary to some recent findings (e.g. De Bandt et al. 2008), cointegration emerges without the necessity to allow for structural breaks neither in the deterministic terms nor in the cointegrating relation. The cointegrating relationship is shown to be driven by unobserved global stochastic trends. Second, by explicitly taking both cointegration and its driving forces into account, the paper estimates the long-run and short-run pass-through elasticities at the panel level and for the individual countries using most recent data covering the period since the introduction of the Euro in 1999. This is achieved by employing the continuously updated fully modified (Cup-FM) and continuously updated bias-corrected (Cup-BC) estimators of Bai et al. (2009), and the dynamic common correlated effects (DCCE) estimator of Chudik and Pesaran (2015), whose advantage over earlier panel estimators is their robustness to cross-sectional dependence induced by unobserved common factors. To the best of our knowledge, this is the first study employing these new econometric techniques for estimation of the ERPT. Despite the technical differences of these estimators, the results they yield are remarkably similar. Following a $10 \%$ depreciation of the exchange rate, the import prices are inclined to rise by $3.7 \%$ on average as estimated by the Cup-FM and Cup-BC estimators, and by $3.4 \%(3.6 \%)$ as estimated by the DCCE estimator. These results indicate only partial pass-through, rejecting both the LCP and PCP hypotheses for the panel as a whole.

The rest of the paper is organized as follows. Section 2 postulates the econometric model for the ERPT and describes the data used for the analysis. Section 3 presents the results of the unit root and cointegration analyses. Section 4 describes the econo-

\footnotetext{
1 The bootstrap version of Westerlund's (2007) tests, meant to robustify them against cross-sectional dependence, is based on the univariate autoregressive sieve bootstrap. The latter has been shown by Smeekes and Urbain (2014) to be invalid for data generating processes characterized by strong cross-sectional dependence, as it does not reproduce the long-run covariance matrix of the data correctly.
} 
metric methodology for the estimation and discusses the empirical results, and Sect. 5 concludes. Auxiliary results are collected in the Appendix.

\section{Model and data}

\subsection{Exchange rate pass-through into import prices}

The analysis is based on the framework adopted by Campa and Goldberg (2005), which is commonly applied in the literature. For notational simplicity, the model is written suppressing the dependence on the cross-sectional dimension $i$. It assumes that the import prices, $P_{t}$, equal the export prices of the country's trading partners, $P_{t}^{x}$, multiplied by the exchange rate, $E_{t}$, expressed per unit of foreign currency:

$$
P_{t}=E_{t} P_{t}^{x}
$$

The export prices comprise the producers' marginal cost, $C_{t}$, and gross markup, $M_{t}$ :

$$
P_{t}^{x}=C_{t} M_{t}
$$

The marginal cost, in turn, depends on the wages in the exporting market, $W_{t}$, and on the demand conditions in the importing market, $Y_{t}$. Denoting the logarithms of all variables by lowercase letters, Eq. (1) thus becomes

$$
\begin{aligned}
p_{t} & =e_{t}+c_{t}+m_{t} \\
& =e_{t}+a_{1} y_{t}+a_{2} w_{t}+m_{t} .
\end{aligned}
$$

The markup is assumed to comprise both a fixed effect $\phi$ and a component depending the macroeconomic conditions, which may be reflected in the exchange rate and/or the demand conditions:

$$
m_{t}=\phi+b_{1} e_{t}+b_{2} y_{t} .
$$

Hence the general ERPT equation in log-linear form becomes

$$
p_{t}=\phi+\left(1+b_{1}\right) e_{t}+\left(a_{1}+b_{2}\right) y_{t}+a_{2} w_{t},
$$

or, more succinctly,

$$
p_{t}=\beta_{0}+\beta_{1} e_{t}+\beta_{2} y_{t}+\beta_{3} w_{t} \text {. }
$$

The primary focus of this paper is the pass-through elasticity given by the coefficient $\beta_{1}$ in Eq. (6). If $\beta_{1}=1$, the pass-through to import prices is said to be complete. Exchange rate fluctuations are reflected one-to-one in the exporters' prices in the domestic market, and in this case producer currency pricing is present. If $\beta_{1}=0$, then exchange rate movements do not affect the prices in the importing market. Exporters 
do not adjust their prices abroad, but rather fully absorb the exchange rate fluctuations in their markup, and hence local currency pricing takes place.

\subsection{Data description}

The dataset comprises a balanced panel ( $T=77, N=19)$ of quarterly time series covering the period 1999Q1-2018Q1 for nineteen European countries: Austria, Belgium, Czech Republic, Denmark, Estonia, Finland, France, Germany, Italy, Lithuania, Luxembourg, Netherlands, Norway, Poland, Portugal, Spain, Sweden, Switzerland, and the UK.

The data on import prices are taken from the Main Economic Indicators (MEI) database of the OECD and reflect the prices of non-commodity imports of goods and services. Nominal effective exchange rate (NEER), weighted by the unit labour costs of a country's trading partners, is taken from the IMF International Financial Statistics (IFS) database for the model's exchange rate variable. It is defined in quantity notation such that an increase represents an appreciation of the domestic currency. This implies that the coefficient $\beta_{1}$ in (6) is expected to be negative, with $\beta_{1}=-1$ indicating complete pass-through. Domestic demand is approximated by real GDP taken from the OECD Quarterly National Accounts database.

The choice of variable for the producers' costs is more involved, since there exists no directly observed variable which controls for the trade shares of the exporting countries. Therefore, a proxy for $w$ has to be constructed from trade data. We follow Bailliu and Fujii (2004), who exploit the real effective exchange rate (REER) based on unit labour costs to create a trade-weighted measure of foreign producers' costs. Denoting the natural logarithm of REER by $q$, it can be represented as

$$
q_{t}=e_{t}+u l c_{t}-u l c_{t}^{*}
$$

where $u l c_{t}$ and $u l c_{t}^{*}$ stand for the domestic and foreign unit labour costs in natural logarithms, respectively. REER is given in price notation, such that an increase reflects a worsening of the international competitive position, and $e$ is given in quantity notation. Solving Eq. (7) for $u l c_{t}^{*}$ yields a trade-weighted proxy for foreign producers' costs, which is then taken as $w$ in the analysis. The unit labour costs series are obtained from the OECD MEI database, while REER and NEER are taken from IMF IFS.

\section{Preliminary analysis}

\subsection{Testing for cross-sectional dependence}

The first step of the analysis is to determine the degree and the source of crosssectional dependence in the panel. This is important in order to select the correct tools for analysing the integration and cointegration properties of the data and for the subsequent estimation of the ERPT. It is well-known that unattended strong crosssectional dependence may result in oversized panel unit root and cointegration tests 
Table 1 Pesaran's (2015) CD statistic for the observed data

\begin{tabular}{lllll}
\hline Variable & CD test statistic & $p$ value & $\overline{\hat{\rho}_{i j}}$ & $\left|\overline{\hat{\rho}_{i j}}\right|$ \\
\hline$\Delta p$ & $42.72^{* * *}$ & 0.000 & 0.375 & 0.390 \\
$\Delta e$ & $42.95^{* * *}$ & 0.000 & 0.377 & 0.483 \\
$\Delta y$ & $52.45^{* * *}$ & 0.000 & 0.460 & 0.461 \\
$\Delta w$ & $12.03^{* * *}$ & 0.000 & 0.106 & 0.172 \\
\hline
\end{tabular}

$\overline{\hat{\rho}_{i j}}$ denotes the average pairwise correlation coefficient while $\left|\overline{\hat{\rho}_{i j}}\right|$ denotes the average absolute pairwise correlation coefficient over cross sections.

${ }^{*},{ }^{* *}$ and ${ }^{* * *}$ denote significance at the $10 \%, 5 \%$ and $1 \%$ level, respectively

and biased estimates of the slope coefficients in Eq. (6) (see, e.g. Banerjee et al. 2004 and Phillips and Sul 2003, 2007).

For this aim, the CD test of Pesaran (2015) is applied to the panel with country cross sections for each variable in Eq. (6). The test assumes weak ${ }^{2}$ cross-sectional dependence under the null hypothesis, such as a spatial-type dependence or dependence driven by common factors affecting only a limited number of units as $N \rightarrow \infty$, for example. Rejection of the null is taken as evidence of the presence of strong crosssectional dependence such as one caused by global (unobserved) common factors. The test statistic is computed as the standardized average of the pairwise correlation coefficients between the series in the panel and is normally distributed under the null hypothesis. To avoid spurious correlation arising from unit roots, the variables have been transformed into first differences. The results are presented in Table 1.

The null of weak cross-sectional dependence is convincingly rejected for all variables. This is expected, given the tight economic and financial links between the European countries and the common currency and monetary policy in the euro area. Hence the analysis proceeds taking into account the presence of strong cross-sectional dependence.

\subsection{Unit root and cointegration analysis}

\subsubsection{Unit root testing}

Next the integration and cointegration properties of the time series are examined by second-generation panel unit root tests which are robust to cross-sectional dependence. In particular, the simple panel unit root test of Pesaran (2007) and the meta-analytic tests of Demetrescu et al. (2006) and Hanck (2013) are applied to the panel with country cross sections of each variable in Eq. (6). ${ }^{3}$ The latter two tests belong to the classes of quantile combination methods and order statistic methods, respectively. Cheng and Sheng (2017) recommend combining tests from these two methods in order to maxi-

\footnotetext{
${ }^{2}$ For definitions of weak and strong cross-sectional dependence refer to Chudik et al. (2011).

${ }^{3}$ More details on the computation of the tests by Hanck (2013) and Demetrescu et al. (2006) are given in the Appendix.
} 
mize power when uncertain about the expected number of false individual hypotheses, albeit their proposed "combination of 'combinations of $p$ values" " approach is valid under cross-sectional independence and thus not applied here. All three chosen tests have been demonstrated by Sheng and Yang (2012) to exhibit good finite-sample properties in the case of strong cross-sectional dependence. Tables 8, 9 and 10 in the Appendix summarize the results. The test of Pesaran (2007) rejects only for the exchange rate series at lags 1,2, 3 and 4 and for the import price series at lag 1 (Table $10)$. On the other hand, a unit root at the panel level cannot be rejected for any variable in levels by both the tests of Hanck (2013) and Demetrescu et al. (2006) (Tables 8 and 9). All three tests reject the presence of a unit root in the first-differenced variables. ${ }^{4}$ Hence there is prevailing evidence of the presence of unit roots in all variables in the model.

\subsubsection{Cointegration testing}

The next step in the analysis is to test the system of all four observed variables for cointegration. For this purpose, the meta-analytic test of Arsova and Örsal (2020) is employed. Similarly to the panel unit root test of Hanck (2013), this test is too based on Simes' multiple testing procedure, where $p$ values from individual-unit likelihoodratio (LR) cointegration rank tests of Saikkonen and Lutkepohl (2000) (SL) are used. Two versions of the latter test are considered, one allowing for a deterministic time trend both in the variables in levels and in the error-correction (EC) term and one allowing for a trend only in the variables in levels. Denoting the cointegrating rank of the system for country $i$ by $r_{i}$, the null hypothesis of the test is $H_{0}: r_{i}=r$, where $r=0,1,2,3$ denotes the common cointegrating rank in a sequential testing procedure. The alternative hypothesis is $H_{1}: r_{i}>r$ for at least one $i$.

The results are presented in Table 2. As the smallest individual $p$ value for testing $H_{0}: r=0$ by the first variant of the SL test is lower than the corresponding Simes' critical value, while $H_{0}: r=1$ cannot be rejected, there is evidence of a single cointegrating relationship in the panel at the 5\% significance level. In order to ensure that the long-run equilibrium connects not only a certain pair of variables, the test of Arsova and Örsal (2020) is applied to all eight different bivariate systems. The null hypothesis of no cointegration is rejected for neither pair; the results are omitted for brevity. Hence the equilibrium relationship is more complex, involving at least three or all four of the variables in the system.

\subsubsection{Analysis of the unobserved common and idiosyncratic components}

Having established nonstationarity and the presence of a single long-run equilibrium relationship in the data, the analysis proceeds to uncover their driving forces. For this purpose, the approach of panel analysis of nonstationarity in idiosyncratic and common components (PANIC) is employed, as set out in Bai and $\mathrm{Ng}$ (2004). The time series are decomposed into unobserved common and idiosyncratic components, and

\footnotetext{
4 The results of the tests by Hanck (2013) and Demetrescu et al. (2006) for the variables in first differences are omitted for brevity.
} 


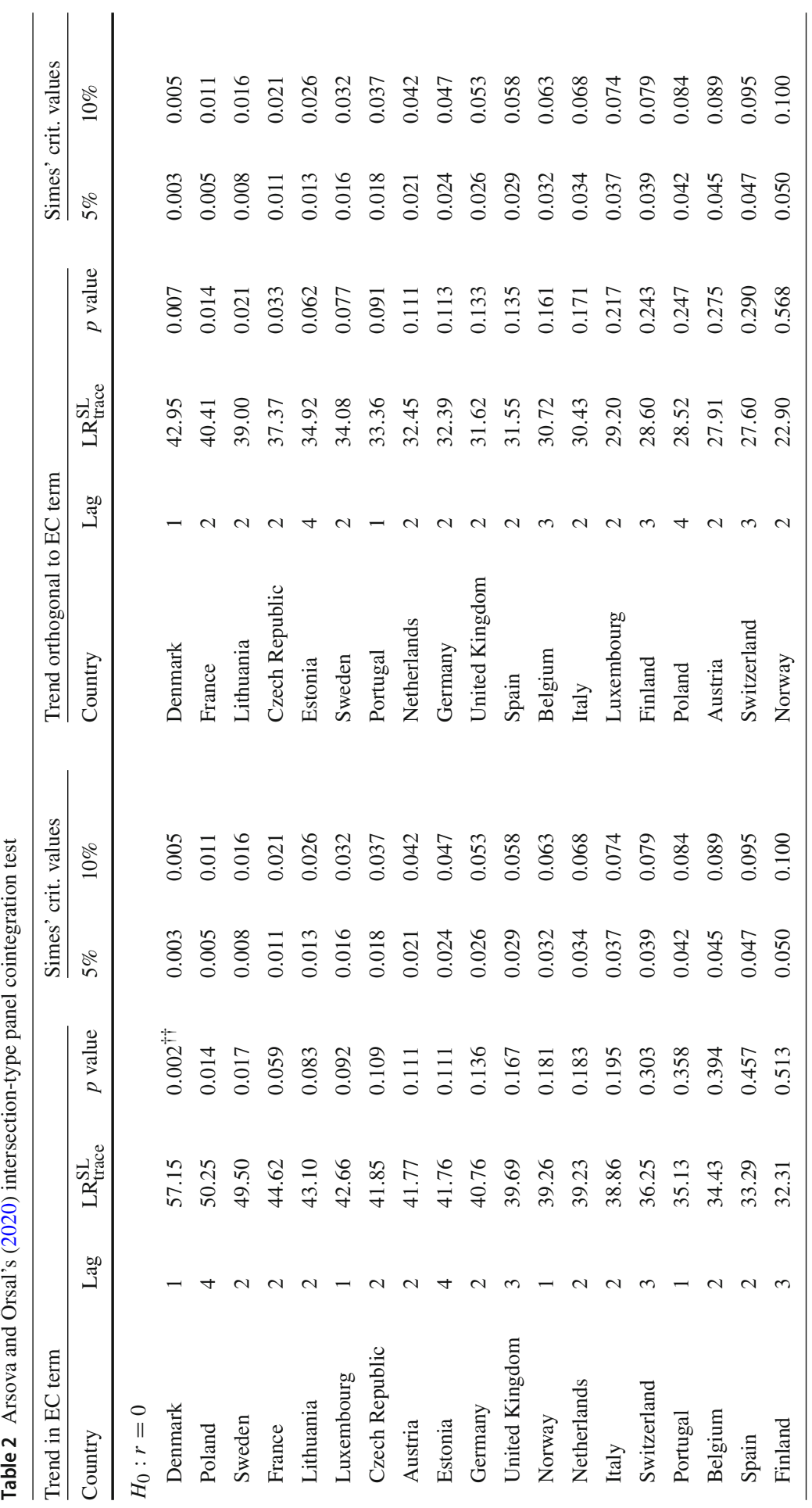




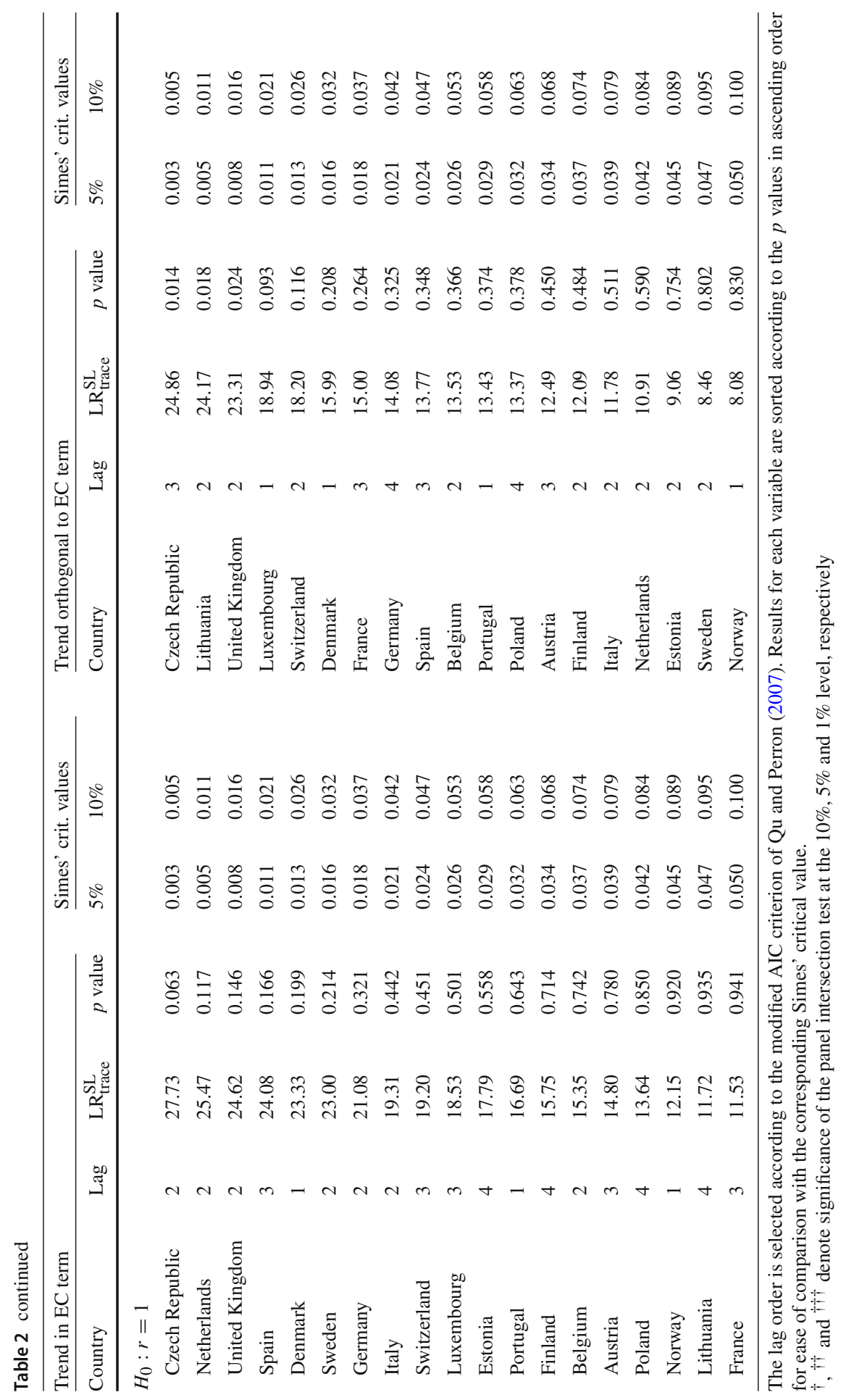


their integration and cointegration properties are analysed separately. The benefit of such analysis is that it provides better understanding of the interconnections among the variables in the system.

Unobserved dynamic common factors are extracted by the method of principal components from the panel for each variable with country cross sections. Prior to the extraction, the observed data are first-differenced. For the panels of import prices, GDP and producer's costs they are also demeaned to account for the observed time trend. The data are also standardized to have unit variance. The number of unobserved common factors for each panel is selected by the criterion of Onatski (2010); the maximum number allowed is six. The criterion picks two factors for the panels of $p$ and $e$, explaining $57 \%$ and $75 \%$ of the variation in the data, respectively. For each of the panels of $y$ and $w$, a single factor is chosen, explaining $52 \%$ and $23 \%$ of the total variation, respectively.

Once the estimated variable-specific common factors are extracted and subtracted from the first-differenced (and potentially demeaned) observations, the remaining residuals are accumulated to yield estimates $\hat{e}_{i, t}^{x}$ of the idiosyncratic components for each variable and cross-sectional unit, $x \in\{p, e, y, w\}$. The estimated idiosyncratic components are then tested for unit roots by the $P_{a}, P_{b}$, and PMSB tests proposed by Bai and $\mathrm{Ng}$ (2010). Table 3 presents the results. The null hypothesis of a unit root cannot be rejected for either panel.

Next, the cointegration properties of the idiosyncratic components are examined by the PSL def test of Arsova and Örsal (2018) and the $P_{\Phi^{-1}}^{*}$ test of Örsal and Arsova (2017). The first test computes the panel test statistic as the standardized average of the individual LR trace statistics of Saikkonen and Lutkepohl (2000) computed from defactored data, while the second one combines the $p$ values of these statistics by the inverse normal method. Both statistics have a limiting $N(0,1)$ distribution under the null hypothesis of a common cointegrating rank $H_{0}: r_{i}=r, \forall i$, whereas the rejection region for the panel-SL test is in the right tail, and for the $P_{\Phi^{-1}}^{*}$ test in the left tail, respectively. Örsal and Arsova (2017) show that the $P_{\Phi^{-1}}^{*}$ exhibits better finitesample properties than the panel-SL test in some situations. The value of the $\mathrm{PSL}_{\mathrm{def}}^{J}$ test statistic under the null of no cointegration is 0.2 , while that of the $P_{\Phi^{-1}}^{*}$ is -1.33 , which is significant at the $10 \%$ level. As neither test rejects the null of cointegrating rank one $\left(\mathrm{PSL}_{\mathrm{def}}^{J}=-2.13\right.$ and $P_{\Phi^{-1}}^{*}=4.99$ in this case), we conclude that there is

Table 3 Bai and Ng's (2010) panel unit root tests for the estimated idiosyncratic components

\begin{tabular}{llrrr}
\hline Idiosyncratic component & Avg. volatility & $P_{a}$ & \multicolumn{1}{c}{$P_{b}$} & PMSB \\
\hline$\hat{e}^{p}$ & 0.037 & -0.005 & -0.005 & 0.027 \\
$\hat{e}^{e}$ & 0.058 & 1.221 & 1.825 & 2.893 \\
$\hat{e}^{y}$ & 0.034 & -0.758 & -0.682 & -0.585 \\
$\hat{e}^{w}$ & 0.035 & 0.945 & 1.092 & 1.266 \\
\hline
\end{tabular}

Trend is included in the test regressions for $p, y$ and $w$, while only a constant is considered for $e$. All three test statistics have a $N(0,1)$ distribution under the null hypothesis of a unit root with a rejection region in the left tail of the distribution. The average volatility is computed over all cross sections 


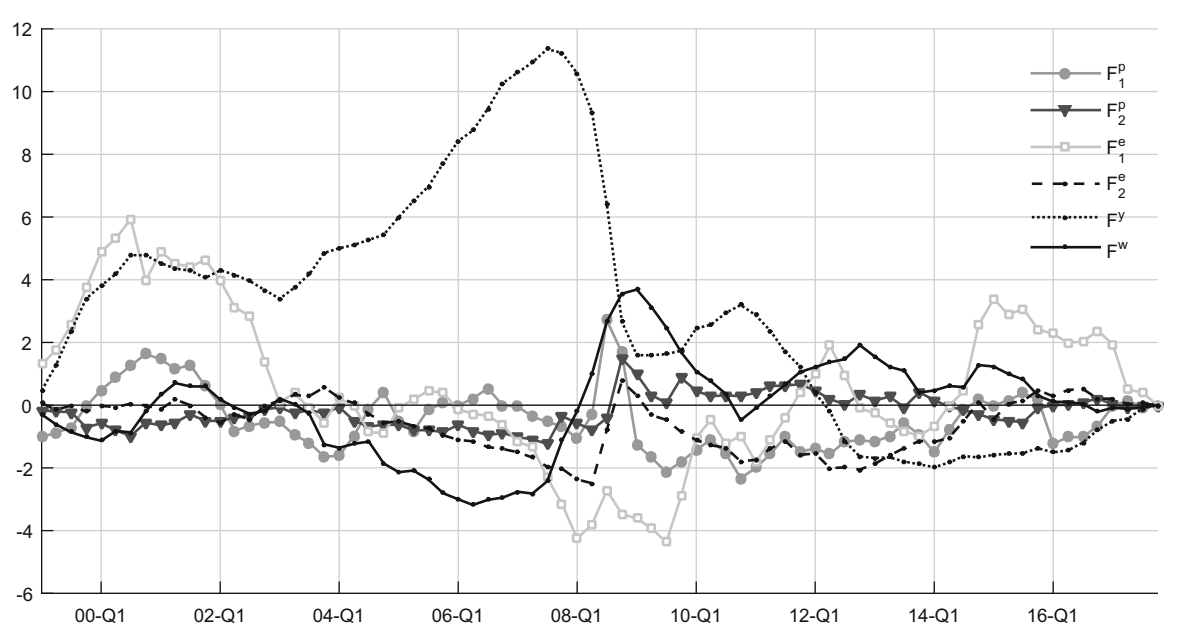

Fig. 1 Extracted common factors from the panel of each model variable. Notes: The common factors are extracted from the panel for each variable with country cross sections. They are denoted as $F_{1}^{p}, F_{2}^{p}, F_{1}^{e}, F_{2}^{e}, F^{y}$, and $F^{w}$, with the superscript signifying the variable-specific panel and the subscript denoting the factor number

some, albeit not very strong, evidence of a single cointegrating relationship among the idiosyncratic components, matching the result for the observed variables.

We next turn our attention to the extracted and accumulated common factors. They are denoted as $F_{1}^{p}, F_{2}^{p}, F_{1}^{e}, F_{2}^{e}, F^{y}$, and $F^{w}$, with the superscript signifying the variable-specific panel they have been extracted from and the subscript denoting the factor number. A graph of the factors is displayed in Fig. 1. It reveals how they all capture the effects of the Global Financial Crisis, reacting mostly simultaneously and with similar turns in the dynamics. Such behaviour hints at possible cointegration among them, which could lead to cross-unit cointegration of the observed variables.

Testing for unit roots in the extracted common factors is carried out by a standard ADF test ${ }^{5}$. The results, presented in Table 4, indicate that the unit root null hypothesis cannot be rejected for any individual factor. The test statistic of the modified inverse normal panel test of Demetrescu et al. (2006) is -0.504, supporting this conclusion.

It is interesting to note the enormous difference between the volatility of the estimated common factors and that of the idiosyncratic components, displayed in Tables 3 and 4, respectively. Even the smallest volatility among those of the factors $(0.52$ for $\left.\hat{F}_{2}^{p}\right)$ is about ten times greater than the largest average volatility of the idiosyncratic components $\left(0.058\right.$ for $\left.\hat{e}^{e}\right)$. Hence we conclude that it is the unobserved common factors which to a large extent determine the behaviour of the observed variables, while the idiosyncratic components have only a minor impact.

Having established the presence of global stochastic trends, we next assess whether they exhibit any cointegration. For more reliable results, the SL test of Saikkonen and Lutkepohl (2000) is employed for each pair of estimated factors, as it is known that

\footnotetext{
5 Bai and $\mathrm{Ng}$ (2004) show that the limiting distributions of the ADF test statistics, computed for common factors extracted from first-differenced or first-differenced and demeaned data, coincide with the usual limiting distributions of the ADF test with a constant only or a constant and linear time trend, respectively.
} 
Table 4 Unit root tests for the estimated common factors

\begin{tabular}{llllll}
\hline Factor & Volatility & Deterministic term & Lag order & $\mathrm{ADF}_{\tau}$ & $p$ value \\
\hline$F_{1}^{p}$ & 0.97 & Trend & 2 & -3.05 & 0.125 \\
$F_{2}^{p}$ & 0.52 & Trend & 4 & -2.67 & 0.254 \\
$F^{y}$ & 2.42 & Trend & 1 & -1.89 & 0.651 \\
$F^{w}$ & 0.83 & Trend & 2 & -2.13 & 0.522 \\
$F_{1}^{e}$ & 3.80 & Const & 2 & -2.17 & 0.496 \\
$F_{2}^{e}$ & 1.53 & Const & 1 & -3.03 & 0.131 \\
\hline
\end{tabular}

$\mathrm{ADF}_{\tau}$ denotes the augmented Dickey-Fuller test statistic. The lag order is selected according to the modified AIC (MAIC) criterion of Ng and Perron (2001). The $p$ values are computed as in MacKinnon (1996); the author is grateful to Christoph Hanck for providing the GAUSS code

Table 5 SL cointegration tests for the estimated common factors

\begin{tabular}{|c|c|c|c|c|c|c|c|}
\hline \multicolumn{4}{|c|}{ Trend in EC term } & \multicolumn{4}{|c|}{ Trend orthogonal to EC term } \\
\hline Factors & Lag order & $\mathrm{LR}_{\text {trace }}^{\mathrm{SL}}$ & $p$ value & Factors & Lag order & $\mathrm{LR}_{\text {trace }}^{\mathrm{SL}}$ & $p$ value \\
\hline$F_{1}^{p}, F_{2}^{p}$ & 2 & 20.81 & $0.006^{* * *}$ & $F_{2}^{p}, F^{w}$ & 4 & 19.59 & $0.001^{* * *}$ \\
\hline$F_{2}^{p}, F^{w}$ & 4 & 18.01 & $0.020^{* *}$ & $F_{1}^{p}, F^{w}$ & 3 & 16.81 & $0.002^{* * *}$ \\
\hline$F_{1}^{p}, F^{w}$ & 3 & 16.90 & $0.032^{* *}$ & $F_{1}^{p}, F_{2}^{p}$ & 2 & 16.60 & $0.003^{* * *}$ \\
\hline$F_{2}^{e}, F^{w}$ & 3 & 13.75 & 0.105 & $F^{y}, F^{w}$ & 4 & 14.53 & $0.007^{* * *}$ \\
\hline$F_{1}^{e}, F^{y}$ & 3 & 12.52 & 0.159 & $F_{2}^{e}, F^{w}$ & 3 & 13.69 & $0.010^{* * *}$ \\
\hline$F_{2}^{p}, F_{1}^{e}$ & 4 & 12.45 & 0.163 & $F_{1}^{e}, F^{w}$ & 2 & 12.88 & $0.014^{* *}$ \\
\hline$F_{1}^{e}, F^{w}$ & 2 & 12.43 & 0.163 & $F_{1}^{e}, F^{y}$ & 3 & 12.50 & $0.016^{* *}$ \\
\hline$F_{1}^{p}, F_{1}^{e}$ & 3 & 11.73 & 0.205 & $F_{1}^{P}, F^{y}$ & 3 & 11.91 & $0.021^{* *}$ \\
\hline$F_{2}^{p}, F^{y}$ & 4 & 11.15 & 0.244 & $F_{2}^{p}, F_{1}^{e}$ & 4 & 11.59 & $0.024^{* *}$ \\
\hline$F_{1}^{p}, F_{2}^{e}$ & 2 & 10.63 & 0.284 & $F_{2}^{p}, F^{y}$ & 4 & 11.45 & $0.026^{* *}$ \\
\hline$F_{1}^{P}, F^{y}$ & 3 & 10.12 & 0.327 & $F_{1}^{p}, F_{2}^{e}$ & 2 & 10.82 & $0.034^{* *}$ \\
\hline$F^{y}, F^{w}$ & 4 & 9.96 & 0.342 & $F_{1}^{p}, F_{1}^{e}$ & 3 & 10.03 & $0.048^{* *}$ \\
\hline$F_{2}^{e}, F^{y}$ & 3 & 7.76 & 0.574 & $F_{2}^{e}, F^{y}$ & 3 & 7.78 & 0.120 \\
\hline$F_{2}^{p}, F_{2}^{e}$ & 4 & 5.99 & 0.776 & $F_{2}^{p}, F_{2}^{e}$ & 4 & 6.34 & 0.208 \\
\hline$F_{1}^{e}, F_{2}^{e}$ & 1 & 5.14 & 0.858 & $F_{1}^{e}, F_{2}^{e}$ & 1 & 5.50 & 0.282 \\
\hline
\end{tabular}

The lag order is selected according to the modified AIC criterion of Qu and Perron (2007). Results for each variable are sorted according to the $p$ values in ascending order for ease of comparison with the corresponding critical value of Hommel's (1988) procedure.

$*, * *$ and ${ }^{* * *}$ denote significance at the $10 \%, 5 \%$ and $1 \%$ level, respectively

the LR cointegrating rank tests become less powerful in larger systems (see, e.g. Saikkonen and Lutkepohl 2000). Table 5 displays the results.

At first glance, there seems to exist a cointegrating relationship between almost any pair of factors considered when allowing for no trend in the cointegrating relation. However, the results of these tests are highly correlated, and one must take the nature of such multiple testing into account. In order to select only the meaningful rejections, Hommel (1988) proposes a procedure which controls the family-wise error rate at a 
chosen significance level $\alpha$. Details on Hommel's procedure can be found in Hanck (2013), whose exposition is briefly reproduced here for convenience. Let the ordered $p$ values of $n$ tests be $p_{(1)}^{*} \leq \ldots \leq p_{(n)}^{*}$ and $\mathbb{N}_{n}$ denote the set of all natural numbers between 1 and $n$. Selecting the meaningful rejections by the Hommel's procedure is then carried out in two steps: (A) Compute $j=\max \left\{i \in \mathbb{N}_{n}: p_{(n-i+k)}^{*}>\frac{k \alpha}{i}, \forall k \in\right.$ $\mathbb{N}_{i}$, and (B) If $p_{(n)}^{*} \leq \alpha$, reject all $H_{i, 0}$; else, reject those $H_{i, 0}$ for which $p_{i}^{*} \leq \frac{\alpha}{j}$.

Following this procedure, $j=10$ is computed, and the corresponding Hommel's critical values at the $5 \%$ and $10 \%$ significance levels are 0.005 and 0.01 , respectively. Hence, only the first five rows in the second panel of Table 5 can be considered genuine rejections at the $10 \%$-level; at the 5\%-level it would only be the first three. We may therefore conclude that two global stochastic trends exist among the extracted common factors: one which is shared by $F_{1}^{p}, F_{2}^{p}, F^{y}, F^{w}$ and $F_{2}^{e}$, and one driving $F_{1}^{e}$.

By analysing the factor loadings (see Table 11 in the Appendix), $F_{1}^{e}$ may be identified as the Euro-exchange-rate factor, which is perhaps not surprising, as the dataset features both countries in and outside the euro area. On the other hand, $F_{2}^{e}$ can be thought of the factor influencing more the dynamics of the exchange rates of the noneuro area countries (including the newest members of the euro area like Lithuania, for example). Relating these results to those from the cointegration testing of the observed variables (Table 2), we conclude that there is much more evidence in favour of a longrun equilibrium relationship in the ERPT for non-euro area countries than it is for euro area ones. One explanation for this phenomenon may lie in the fact that the import prices in euro area countries, whose principal share of imports come from other euro area countries, react much less to aggregate exchange rate fluctuations because these are basically zero between the one and the same currency. This leads us to believe that the ERPT estimates would be lower for the older member countries of the euro area than they would be for the newer ones or the countries outside the euro area.

The results of the unit root and cointegration analysis can be summarized as follows. All variables in the log-linear ERPT relationship in Eq. (6) are integrated of order one. There is evidence of a single cointegrating relationship at the panel level linking the observed variables, suggesting that the average long-run elasticity of the exchange rate is different from zero. It is worth noting that, contrary to the results of De Bandt et al. (2008), this relationship emerges without the necessity to consider structural breaks, neither in the deterministic components, nor in the long-run equilibrium. This is so because of the present cross-unit cointegration driven by unobserved common factors. These factors capture the major exogenous shocks such as the Global Financial Crisis which, in turn, force the observed variables to react more or less simultaneously and in a similar fashion. Although the data dynamics are mostly determined by six unobserved common factors (two for the panel of import prices, two for the panel of nominal exchange rate and one for each of the domestic demand and producer's cost proxy panels), the driving forces behind them are only two distinct global stochastic trends. One of them is shared by the import prices panel, the domestic demand panel, the producer's costs panel, and by the exchange rate data for countries outside the euro area as well as newer member countries of the euro area. The second global stochastic trend can be viewed as a Euro-nominal-exchange-rate factor, influencing mostly the exchange rate series of the euro area countries. The idiosyncratic components of the 
data, although with much less impact than the common components, are also nonstationary and cointegrated by a single relationship. These findings lead us to expect more significant ERPT elasticities for non-euro area countries than for euro area ones.

\section{ERPT estimation}

Having established the presence of a long-run equilibrium relationship at the panel level, the next step is to estimate the ERPT equation (6). However, the presence of cross-sectional dependence, depending on its nature, may yield the results of earlier panel regression estimators either biased, inconsistent or inefficient [see, e.g. Phillips and Sul (2003, 2007) and Moon and Weidner (2017)]. Further, cross-unit cointegration has also been shown by Urbain and Westerlund (2006) to pose an issue in pooled ordinary least squares estimation. Hence an estimator which takes into account both cointegration and cross-sectional dependence induced by global stochastic trends is needed.

Two suitable approaches have recently been proposed in the literature. The first one, put forward by Bai et al. (2009), features two estimators: the continuously updated biascorrected (Cup-BC) and the continuously updated fully modified (Cup-FM) estimator. They estimate level relationships in panel cointegration models where unobserved common factors drive the dependence in the regression errors and which may also be correlated with the regressors. This methodology has been widely applied in recent empirical panel data studies, employed by e.g. Bodart et al. (2015) for estimation of a long-run relationship between real exchange rates and commodity prices, and by Örsal (2017) for estimation of a long-run money demand relation.

The second approach, using a common correlated effects (CCE) mean-group (MG) estimator, is due to Chudik and Pesaran (2015). They extend earlier work of Pesaran (2006) to panel data models allowing for lagged dependent variables and weakly exogenous regressors. The residual dependence induced by the unobserved common factors is captured by cross-sectional averages of the observed variables included as additional regressors in the individual equations. Details on the estimation by each estimator are briefly outlined next, while the empirical results are discussed in Sect. 4.3.

\subsection{The Cup-BC and Cup-FM estimators of Bai et al. (2009)}

The ERPT equation (6) can be written in the Bai et al. (2009) estimation framework as

$$
\begin{aligned}
& p_{i t}=\beta_{0}+\beta_{1} e_{i t}+\beta_{2} y_{i t}+\beta_{3} w_{i t}+u_{i t}, \\
& u_{i t}=\lambda_{i}^{\prime} f_{t}+\varepsilon_{i t} .
\end{aligned}
$$

The errors $\varepsilon_{i t}$ are assumed to be stationary and only weakly cross-sectionally dependent, while the unobserved common factors in the $(r \times 1)$-vector $f_{t}$ are allowed to be $I(0), I(1)$ or a mixture of the two. They are treated as parameters and estimated together with the common slope coefficients $\beta=\left(\beta_{1}, \beta_{2}, \beta_{2}\right)$ in an iterative procedure. 
Table 6 ERPT estimation results by the Cup-BC and Cup-FM estimators

\begin{tabular}{lll}
\hline Variable & Cup-BC & Cup-FM \\
\hline Nominal exchange rate elasticity $\hat{\beta}_{1}$ & $-0.372^{* * *}$ & $-0.369^{* * *}$ \\
& {$[0.029]$} & {$[0.029]$} \\
Domestic demand elasticity $\hat{\beta}_{2}$ & -0.041 & -0.009 \\
& {$[0.044]$} & {$[0.042]$} \\
Producers' costs elasticity $\hat{\beta}_{3}$ & -0.011 & 0.007 \\
& {$[0.035]$} & {$[0.035]$} \\
\hline
\end{tabular}

Standard errors are presented in brackets.

$*, * *$ and ${ }^{* * *}$ denote significance at the $10 \%, 5 \%$ and $1 \%$ level, respectively

Albeit consistent, the resulting $\hat{\beta}_{\text {Cup }}$ estimator has been shown to be asymptotically biased; hence, a bias correction is necessary. The Cup-BC and the Cup-FM estimators differ with regard to when this bias correction takes place. With the Cup-BC, it is applied only once at the final iteration, while with the Cup-FM the correction is made at each iteration. $\hat{\beta}_{\text {Cup }}$ is shown to be at least $T$-consistent regardless of the integration order (zero or one) of the factors or that of the regressors. Being pure panel estimators, however, both the Cup-FM and the Cup-BC assume homogeneity of the coefficients across cross sections and hence do not produce individual-unit results, which may be viewed as a drawback in practice.

In order to account for the trending behaviour of the variables $p, y$ and $w$, Eq. (9) is estimated with demeaned and detrended series, as suggested by Bai et al. (2009). ${ }^{6}$ The number $r$ of residual common factors is selected by the criterion of Onatski (2010). It picks two factors which account for $59 \%$ of the variance of the first-stage residuals $\hat{u}_{i t}$.

The results are presented in Table 6 . The actual estimates of the elasticity parameters are quite similar across the two estimators. The nominal exchange rate elasticity, which is the only statistically significant coefficient, is estimated by both the Cup-FM and the Cup-BC as $\hat{\beta}_{1}=-0.37$. This implies that a $10 \%$ depreciation in the exchange rate would lead to an average increase of $3.7 \%$ in the import prices. The results are discussed in more detail in Sect. 4.3.

Figure 2 in the Appendix presents a graph of the estimated residual common factors. ${ }^{7}$ The Global Financial Crisis manifests itself in the two spikes in 2008Q4 and 2009Q1, respectively. Analysis of the Cup-FM ${ }^{8}$ model residuals, depicted in Fig. 3 in the Appendix, reveals that the two factors adequately capture the effects of the crisis, as no further common shocks can be observed. Applying Demetrescu et al.'s (2006) panel unit root test to the estimated residuals yields a value of -5.25 for Hartung's test statistic with $\kappa=0.2$, which points to their stationarity. This leads us to the conclusion that no model assumptions have been violated.

\footnotetext{
6 The model has been estimated using the GAUSS code available at Chihwa Kao's personal website.

7 These factors, common to the first-stage residuals of the Cup-FM and Cup-BC models, are not to be confused with the common factors extracted from the panel formed by each variable.

${ }^{8}$ Results for the residuals of the CUP-BC estimation are very similar and omitted for brevity.
} 


\subsection{The dynamic CCE estimator of Chudik and Pesaran (2015)}

The second approach considered for the estimation of the ERPT equation (6) is the panel autoregressive distributed-lag (ARDL) model with multifactor error structure proposed by Chudik and Pesaran (2015). This framework differs from the specification of Bai et al. (2009) in that it allows for (a) lagged values of the dependent and independent variables as additional regressors and (b) heterogeneous coefficients $\beta_{j, i},(i=1, \ldots, N, j=0, \ldots, 3)$, for each unit, which are then combined in a mean-group (MG) estimator. As in Bai's framework, unobserved common factors in the residuals drive the strong cross-sectional dependence. The common factors, however, are not explicitly estimated from the data. Instead, they are approximated by cross-sectional averages of the observed model variables and the resulting regressions are estimated individually for each unit by ordinary least squares. A necessary condition for the validity of the resulting CCE MG estimator is that the number of unobserved common factors be no more than the observed variables in the system. This assumption is likely to be satisfied in our case, as Onatski's (2010) criterion picks two factors in the residuals of the panel regression in Eq. (9). Initially proposed for stationary factors (Pesaran 2006), the CCE approach has been proved to be valid for integrated factors as well (Kapetanios et al. 2011).

With regard to the assumed weak exogeneity of the regressors, also necessary for the validity of the dynamic CCE (DCCE) MG estimator, we note that the preceding analysis is valid upon the assumption that changes in the import prices do not contemporaneously affect exchange rates, domestic demand or producers' costs. While this assumption is commonly made in the empirical ERPT literature, a discussion is warranted as to how it relates to our data set, which consists of countries within and outside of the euro area. For the individual countries within the euro area, the assumption should be innocuous as each country independently is small relative to the euro area. Therefore, it is unlikely that the European Central bank reacts to individual member states' changes in import prices via monetary policy actions, which in turn could affect the currency markets. The literature on ERPT has shown that the short-run impacts of exchange rate changes are highly heterogeneous; thus, it is not expected all import prices to react in the same manner (Campa and Goldberg 2005; Ben Cheikh and Rault 2017). For non-euro area member states, on the other hand, it is likely that the respective central banks intervene following more drastic price developments. Indeed, if import prices rise considerably, this may cause an increase in inflation and potentially trigger a monetary policy reaction, which could, in turn, affect exchange rates. It is unlikely, however, that this transmission would be completed within one quarter, as central banks typically implement monetary policy measures in response to year-onyear inflation (Brun-Aguerre et al. 2017). Furthermore, they typically target headline inflation, while ERPT studies have concluded that the second-stage pass-through is typically low (Campa and Goldberg 2005; Comunale and Kunovac 2017). It is nevertheless important to point out that one strand of the empirical macroeconomic literature on EPRT advocates the use of structural models as opposed to single-equation models in order to accommodate endogeneity between the variables (e.g. Forbes et al. (2018), Comunale and Kunovac (2017)). 
To cast the ERPT model (6) into the CCE-framework, we begin with Eq. (9), allowing for heterogeneous coefficients: ${ }^{9}$

$$
\begin{aligned}
& p_{i t}=\beta_{0, i}+\beta_{1, i} e_{i t}+\beta_{2, i} y_{i t}+\beta_{3, i} w_{i t}+u_{i t}, \\
& u_{i t}=\lambda_{i}^{\prime} f_{t}+\varepsilon_{i t} .
\end{aligned}
$$

Taking the cointegrating relationship explicitly into account, we then put it in an error-correction (EC) form:

$$
\begin{aligned}
\Delta p_{i t}= & \beta_{0, i}+\rho_{i}\left(p_{i, t-1}-\beta_{1, i} e_{i, t-1}-\beta_{2, i} y_{i, t-1}-\beta_{3, i-1} w_{i, t-1}-\lambda_{i}^{\prime} f_{t-1}\right) \\
& +\gamma_{1, i} \Delta e_{i t}+\gamma_{2, i} \Delta y_{i t}+\gamma_{3, i} \Delta w_{i t}+\gamma_{i, f} \Delta f_{t}+\varepsilon_{i t},
\end{aligned}
$$

so that, by re-arranging, we get

$$
\begin{aligned}
\Delta p_{i t}= & \pi_{0, i}+\pi_{e c, i} p_{i, t-1}+\pi_{1, i} e_{i, t-1}+\pi_{2, i} y_{i, t-1}+\pi_{3, i} w_{i, t-1}+\pi_{1 f, i} f_{t-1} \\
& +\pi_{4, i} \Delta e_{i t}+\pi_{5, i} \Delta y_{i t}+\pi_{6, i} \Delta w_{i t}+\pi_{2 f, i} \Delta f_{t}+\varepsilon_{i t} .
\end{aligned}
$$

The long-run parameters $\beta_{j, i},(i=1, \ldots, N, j=1,2,3)$, can be recovered from the coefficients of Eq. (13) as $\beta_{j, i}=-\pi_{j, i} / \pi_{e c, i}$, while the short-run parameters $\pi_{j, i}, j=4,5,6$, are estimated directly. The term $\pi_{e c, i}$ describes the speed of adjustment to equilibrium, and its statistical significance may be viewed as an additional evidence of the presence of cointegration.

For the estimation, the unobserved common factors $f_{t}$ in Eq. (13) are replaced by cross-sectional averages of the observed variables:

$$
\begin{aligned}
\Delta p_{i t}= & \pi_{0, i}+\pi_{e c, i} p_{i, t-1}+\pi_{1, i} e_{i, t-1}+\pi_{2, i} y_{i, t-1}+\pi_{3, i} w_{i, t-1} \\
& +\pi_{4, i} \Delta e_{i t}+\pi_{5, i} \Delta y_{i t}+\pi_{6, i} \Delta w_{i t} \\
& +\pi_{1, i}^{*} \Delta \bar{p}_{t}+\pi_{2, i}^{*} \bar{p}_{t-1}+\pi_{3, i}^{*} \bar{e}_{t-1}+\pi_{4, i}^{*} \bar{y}_{t-1}+\pi_{5, i}^{*} \bar{w}_{t-1} \\
& +\pi_{6, i}^{*} \Delta \bar{e}_{t}+\pi_{7, i}^{*} \Delta \bar{y}_{t}+\pi_{8, i}^{*} \Delta \bar{w}_{t}+\varepsilon_{i t} .
\end{aligned}
$$

So far, Eq. (14) constitutes the model for the standard CCE MG estimator of Pesaran (2006). As Chudik and Pesaran (2015) show, finite-sample bias arises in the dynamic panel model with weakly exogenous regressors and recommend the inclusion of sufficient number $(s)$ lagged values of the cross-sectional averages to mitigate it. Their suggested rule of thumb, $s=\operatorname{int}\left(T^{1 / 3}\right)$, gives $\hat{s}=4$ in our case. Hence the complete model to be estimated by the DCCE estimator becomes

$$
\begin{aligned}
\Delta p_{i t}= & \pi_{0, i}+\pi_{e c, i} p_{i, t-1}+\pi_{1, i} e_{i, t-1}+\pi_{2, i} y_{i, t-1}+\pi_{3, i} w_{i, t-1} \\
& +\pi_{4, i} \Delta e_{i t}+\pi_{5, i} \Delta y_{i t}+\pi_{6, i} \Delta w_{i t} \\
& +\pi_{1, i}^{*} \Delta \bar{p}_{t}+\pi_{2, i}^{*} \bar{p}_{t-1}+\pi_{3, i}^{*} \bar{e}_{t-1}+\pi_{4, i}^{*} \bar{y}_{t-1}+\pi_{5, i}^{*} \bar{w}_{t-1} \\
& +\pi_{6, i}^{*} \Delta \bar{e}_{t}+\pi_{7, i}^{*} \Delta \bar{y}_{t}+\pi_{8, i}^{*} \Delta \bar{w}_{t}
\end{aligned}
$$

\footnotetext{
9 The exposition is similar to that of Eberhardt and Presbitero (2015), whose Stata code for the dynamic CCE MG estimator has been used for the estimation.
} 


$$
\begin{aligned}
& +\sum_{l=1}^{4} \pi_{9, l, i}^{*} \Delta \bar{p}_{t-l}+\sum_{l=1}^{4} \pi_{10, l, i}^{*} \Delta \bar{e}_{t-l} \\
& +\sum_{l=1}^{4} \pi_{11, l, i}^{*} \Delta \bar{y}_{t-l}+\sum_{l=1}^{4} \pi_{12, l, i}^{*} \Delta \bar{w}_{t-l}+\varepsilon_{i t} .
\end{aligned}
$$

The results from the estimation at the panel level are listed in Table 7, while results from the individual-country models are available in Table 12 in the Appendix.

The first two columns present the results from the estimation with the standard mean-group panel estimator of Pesaran and Smith (1995), included to illustrate what the effect of unattended cross-sectional dependence would be. The residual correlation as measured by Pesaran's (2015) CD test is highly significant, and the resulting estimates are therefore likely to be biased and inconsistent (Moon and Weidner 2017).

The middle two columns of Table 7 present the results from the DCCE estimator with a constant or a constant and a linear time trend, respectively. Following Eberhardt and Presbitero (2015), for the DCCE models we present two sets of long-run average coefficients, which differ depending on when the averaging ${ }^{10}$ over cross sections is carried out. For the long-run average coefficients (LRA), the estimated individual EC-model coefficients are averaged first and then the long-run average coefficient is computed, while for the average long-run coefficients (ARL) the individual long-run coefficients are computed first and then averaged. We note that the LRA and ARL estimates are quite similar with overlapping confidence intervals. The CD test statistic has much lower values, indicating that the inclusion of the cross-sectional averages controls well for the dependence. Nevertheless, it is significant at the $1 \%$ level. Analysis of the regression residuals has identified a common shock due to the Great Recession as a possible reason for the elevated correlation. Hence the model equation (15) is augmented by a dummy variable which has the value one in 2008Q3, 2008Q4 and 2009Q1, and zero otherwise. It is then included as an observed common factor in the estimation.

The results from this augmented DCCE model are presented in the last two columns of Table 7. The CD test statistic (1.30 in the constant only and 0.51 in the trend case, respectively) is not statistically significant any more, showing that there is no strong cross-sectional dependence left among the residuals after the inclusion of the Great Recession dummy variable. Its value is nevertheless higher in the constant only case, suggesting that the higher average cross-sectional correlation among the residuals may be due to omitted incidental trends. Turning to the estimation results with trend included (last column), we note that more than a fifth $(21 \%)$ of the time trend coefficients are significant at the 5\% level, suggesting that the trending behaviour of the variables must be accounted for. Furthermore, only when including a linear time trend in the model does the estimated long-run coefficient for the producers costs proxy become statistically significant. The insignificant value of the $\mathrm{CD}$ test statistic serves also as evidence that the number of unobserved common factors is less than the

\footnotetext{
10 Outlier-robust means are employed in both cases. Results with unweighted means are similar and omitted for brevity.
} 


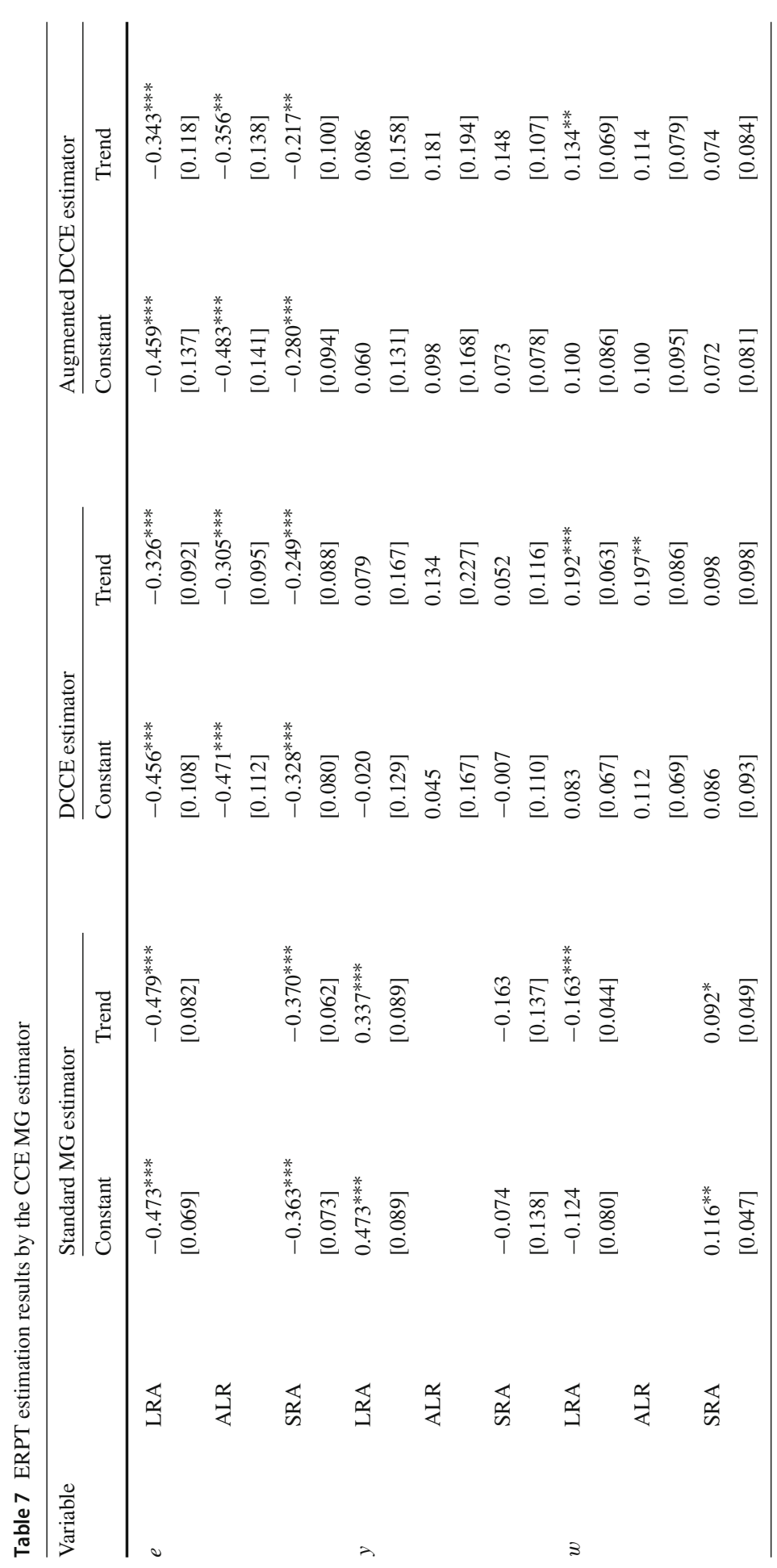




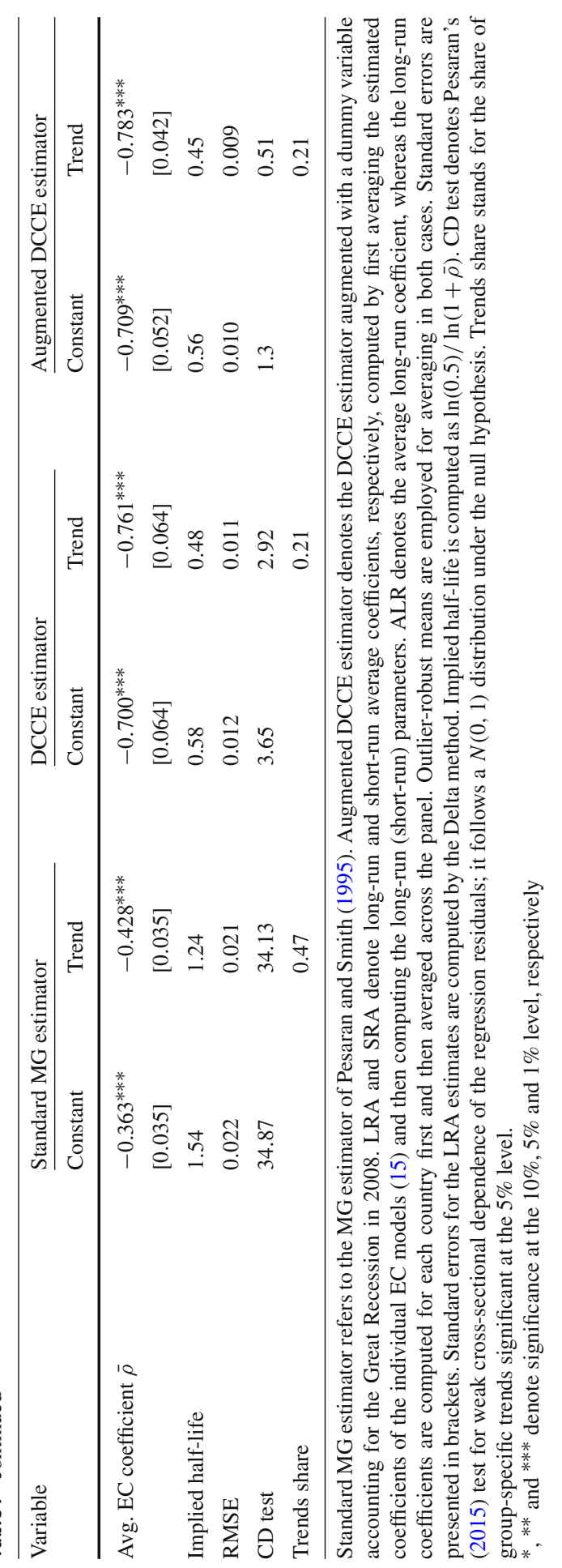


number of observed variables in the system, thus rendering the DCCE estimator valid in this regard.

The residuals of the augmented DCCE model with trend are analysed as a diagnostic check. Demetrescu et al.'s (2006) panel unit root test yields a value of -16.13 for Hartung's inverse normal test with $\kappa=0.2$, convincingly rejecting the unit root null hypothesis. A plot of the estimated residuals, presented in Fig. 4 in the Appendix, reveals no anomalies which could have resulted from potentially unattended structural breaks.

The next section compares the results from the Bai et al.'s (2009) estimators with those from the augmented DCCE estimator with trend and discusses their implications.

\subsection{Discussion}

The results produced by the Cup-BC, Cup-FM and the DCCE estimators are remarkably similar. The point estimate of the ERPT by both the Cup-BC and Cup-FM estimators is -0.37 with a standard error of 0.03 , while the average long-run ERPT by the DCCE MG estimator (LRA) is -0.34 with a standard error of 0.12 ; the ALR estimate is -0.36 with a standard error of 0.14 . Hence their $95 \%$ confidence bands overlap, and neither includes the borderline values zero or one. Therefore, there is no evidence of PCP or LCP in the long-run, but rather of incomplete and low ERPT at the panel level. The average short-run ERPT coefficient estimated by the DCCE model is -0.22 , which is significantly different from zero at the $5 \%$ level, but not at the $1 \%$. These values are lower than the average exchange rate elasticity of 0.54 reported by Ben Cheikh and Rault (2016) for twelve euro area countries in the period 1990Q3-2012Q4, and also lower than the average of 0.47 for eighteen low-inflation countries in the period 1992-2012, estimated by Ben Cheikh and Louhichi (2016). Thus our results provide further evidence that ERPT has been declining over time, as found in the recent literature (Campa and Goldberg 2005; Ben Cheikh and Rault 2016). This may be attributed to the fact that our data comprises a longer period since the creation of the monetary union, so that a greater degree of convergence to more stable macroeconomic conditions has taken place in most countries of the panel. Another reason, however, might be the significant share of intra-euro area trade, which biases the aggregate ERPT estimates downwards (see Blagov 2020).

Turning our attention to the average error-correction coefficient $\bar{\rho}$, reported in the last column of Table 7, we see that it is highly significant, once again highlighting the presence of cointegration in the system. Its value is -0.783 , which implies high speed of adjustment to equilibrium - the aggregate implied half-life ${ }^{11}$ is just 0.45 quarters.

The importing country's demand is not statistically significant in either model. Domestic demand $y_{i t}$ not being an informative regressor for import prices despite predictions by economic theory is a result found also by other empirical studies, see, e.g. Campa and Goldberg (2005) and Beirne and Bijsterbosch (2009). The long-run elasticity of the producers costs proxy, on the other hand, is found to be significant at the $5 \%$ level by the DCCE MG estimator with a point estimate of 0.134 . This result

\footnotetext{
11 The period of time needed for deviations in import prices to decline by half following a unit shock of the exchange rate.
} 
implies a $1.3 \%$ increase on average in the import prices following a $10 \%$ increase of producers' costs. The mixed signals regarding the significance of the producers costs, given by the two estimators, could result from unit labour costs not being a sufficiently good approximation for the producers' actual costs due to their slowly changing nature, for example. In a single-equation framework such results could raise questions regarding the validity of the ERPT results, as the estimation might be subject to omitted variable bias. In the panel framework, however, the unobserved common factors become a remedy for such problem. Being allowed to be $I(0), I(1)$ or mixture of the two by both models, they capture the effects of any common shocks that influence the import prices and are not contained in the regressors. Hence besides controlling for cross-sectional dependence, the inclusion of unobserved common factors in the regression equations (9) and (13) has the added benefit of guarding against omitted variable bias. Therefore, the results for the exchange rate elasticity remain valid.

To check the robustness of our estimates, the ERPT regressions (9) and (13) have been estimated by including oil price (in natural logarithm) as an additional explanatory variable. It represents a secondary transmission channel, through which exchange rate changes indirectly influence import prices through their effects on commodity prices. The results for the ERPT elasticities, presented in Tables 13 and 14 in Sect. A.4 in the Appendix, are qualitatively the same as for the baseline model.

Finally, we discuss the individual countries' results from the DCCE estimator, presented in Table 12 in the Appendix. The estimated long-run exchange rate coefficients are quite heterogeneous with relatively large standard errors, which is the price to pay for the inclusion of current and lagged values of the cross-sectional averages in the individual equations. The long-run exchange rate elasticity is insignificantly different from zero for most of the older euro area member countries (Austria, Belgium, Finland, France, Luxembourg, Netherlands, Spain) and also for Switzerland and Estonia. Notable exceptions are Germany, Italy, and Portugal. The estimated long-run passthrough coefficients for these countries are $-0.56,-1.13$ and -1.23 , respectively. In general, these results conform with previous findings in the literature of low or nonsignificant ERPT for the "core" EU countries (e.g. Austria, Belgium, France, The Netherlands), and higher, even complete ERPT for the "peripheral" EU countries such as Portugal (e.g. Comunale and Kunovac 2017; Ben Cheikh and Rault 2016). The main exceptions from this rule seem to be Germany, with a statistically significant long-run ERPT of -0.56 , and Spain, whose estimated coefficient is statistically insignificant. Keeping in mind the large standard errors of the estimates in the individual-country models by the DCCE estimator, the result for Germany is not at odds with the estimates from other recent studies (e.g. 0.33 for the period 2005-2018 reported by Blagov (2020)). One possible explanation for Germany's sensitivity to exchange rate fluctuations may be its high degree of trade openness. On the other hand, the long-run ERPT coefficients are significant and with the expected negative sign for all non-euro area countries except for Switzerland: that is, for the Czech Republic (-0.33), Denmark $(-1.46)$, Lithuania $(-1.13)$, Poland $(-0.27)$, Sweden $(-0.84)$ and the UK $(-0.53)$. 


\section{Summary and outlook}

This paper establishes the presence of a long-run equilibrium relationship underlying the ERPT in a panel of nineteen European countries by employing new secondgeneration panel cointegration tests. Taking into account that unobserved global stochastic trends drive the cointegrating relationship and induce cross-sectional dependence in the data, aggregate long- and short-run exchange rate elasticities are estimated by novel panel estimators from most recent data. The results support the findings of earlier studies which report declining ERPT over time.

Future work could broaden the scope of the present analysis in several directions. Firstly, other data on import prices, which distinguish between imports from inside and outside the euro area, could be considered. As argued in Sect. 3, since a significant share of a Eurozone country's imports comes from other Eurozone countries, this may introduce a downward bias in an aggregate ERPT estimate. Monthly data on intraand extra-euro area import prices is available from Eurostat; however, sufficiently long time series exist for only six countries and the euro area as a whole. Hence the large- $N$ panel estimators in this study would not be applicable and other estimation techniques would be needed. Secondly, ERPT to import prices could be investigated at an industry level, as considerable heterogeneity in ERPT elasticities has been reported across different industries (De Bandt et al. 2008; Blagov 2020).

Finally, better understanding of the pricing behaviour of exporters with respect to currency appreciation or depreciation could be gained when considering possible asymmetries in the ERPT. The linear ERPT considered in the present study implies that import prices react in the same way to changes in exchange rate, irrespective of their direction. Some recent studies (e.g. Bussiere 2013; Brun-Aguerre et al. 2017), however, suggest that this may not be the case, as various factors could lead to asymmetric responses of import prices. For example, exporters generally have a higher incentive to pass though a depreciation of the domestic currency in order to maintain their markup. In theory, however, ERPT may both rise or fall following an appreciation of the importing country's currency. Under imperfect competition, exporting firms have market power and they could rather choose not to pass through an appreciation of the domestic currency in order to maximize their profits. This would lead to a higher ERPT in the case of depreciation than in the case of appreciation. However, in a competitive market exporters might prefer to absorb depreciation and to keep prices constant in order to maintain or enhance their market share, leading to the opposite outcome for the ERPT. Empirically, the number of studies considering asymmetric ERPT is still small and they do not provide clear evidence on the presence of asymmetry and its direction for the European countries. ${ }^{12}$ Ignoring potential asymmetry in a long-

\footnotetext{
12 Brun-Aguerre et al. (2017) find no evidence of asymmetric long-run ERPT for Germany, France, Italy, Spain and the Netherlands; they present only weak evidence for Norway and Switzerland and strong evidence for Belgium, Denmark, Finland, Sweden and the UK. Przystupa and Wrobel (2011) report no asymmetry of ERPT in Poland, while Delatte and López-Villavicencio (2012) do find such for Germany, but not for the UK. Most recently, Colavecchio and Rubene (2020) report symmetric ERPT to import and consumer prices in the euro area as a whole; short-lived asymmetry (higher for appreciations than for depreciations) is found in Germany, France and Spain, while asymmetry persisting for more than 2 years is found only for Belgium and Luxembourg (higher for depreciations than for appreciations).
} 
run equilibrium relationship may result in a failure to establish it (Shin et al. 2014), as hypothesizing a linear cointegrating relationship would amount to attempting to average out two different cointegrating relations with potentially different adjustment speeds and adjustment dynamics, whose effects might even cancel each other out. We note that our results strongly support the existence of linear cointegration, which we interpret as evidence that even if sign-asymmetry existed, its effects would have been small. It would nevertheless be worthwhile to formally investigate any sign- and/or size-nonlinearities of the ERPT and to compare their potential effects with the results of this study. We leave this issue for future research.

Acknowledgements Open Access funding provided by Projekt DEAL.

Open Access This article is licensed under a Creative Commons Attribution 4.0 International License, which permits use, sharing, adaptation, distribution and reproduction in any medium or format, as long as you give appropriate credit to the original author(s) and the source, provide a link to the Creative Commons licence, and indicate if changes were made. The images or other third party material in this article are included in the article's Creative Commons licence, unless indicated otherwise in a credit line to the material. If material is not included in the article's Creative Commons licence and your intended use is not permitted by statutory regulation or exceeds the permitted use, you will need to obtain permission directly from the copyright holder. To view a copy of this licence, visit http://creativecommons.org/licenses/by/4.0/.

\section{A Appendix}

\section{A.1 Simes' (1986) intersection test}

Let $p_{1}^{*} \leq \cdots \leq p_{N}^{*}$ be the $p$ values of $N$ individual test statistics. Ordering them as $p_{(1)}^{*} \leq \cdots \leq p_{(N)}^{*}$, the joint null hypothesis $H_{0}:=\bigcap_{i} H_{i, 0}, i=1, \ldots, N$, that all individual null hypotheses are simultaneously true) is rejected by Simes' test at significance level $\alpha$ if

$$
p_{(i)}^{*} \leq \frac{i \alpha}{N} \text { for any } i=1, \ldots, N
$$

Simes (1986) shows that the test is conservative under independence of the individual test statistics, that is

$$
P_{H_{0}}\left\{p_{(i)}^{*} \geq \frac{i \alpha}{N}, i=1, \ldots, N\right\} \geq 1-\alpha .
$$

Simes' intersection method has been introduced to testing for panel unit roots by Hanck (2013) and to testing for panel cointegration in dependent panels by Arsova and Örsal (2020).

\section{A.2 Demetrescu et al.'s (2006) panel unit root test}

Demetrescu et al. (2006) employ the modified inverse normal method of Hartung (1999), in which the dependence is captured by a single correlation coefficient $\rho_{t}$, which can be interpreted as a "mean correlation approximating the case of possibly different correlations between the transformed statistics" (Hartung 1999). The statistic 
has a $N(0,1)$ distribution under the null hypothesis. It is computed as ${ }^{13}$

$$
t\left(\hat{\rho}_{t}^{*}, \kappa\right)=\frac{\sum_{i=1}^{N} t_{i}}{\sqrt{N+\left(N^{2}-N\right)\left(\hat{\rho}_{t}^{*}+\kappa \cdot \sqrt{\frac{2}{(N+1)}}\left(1-\hat{\rho}_{t}^{*}\right)\right)}}
$$

Here $t_{i}=\Phi^{-1}\left(p_{i}^{*}\right)$ denote the probits and the variance of the denominator is augmented with an estimator of the correlation between the individual probits $\hat{\rho}_{t}^{*}$ : $\hat{\rho}_{t}^{*}=\max \left\{-\frac{1}{N-1}, \hat{\rho}_{\mathrm{t}}\right\}$, where $\hat{\rho}_{\mathrm{t}}=1-\frac{1}{N-1} \sum_{i=1}^{N}\left(t_{i}-\frac{1}{N} \sum_{i=1}^{N} t_{i}\right)^{2}$.

The correction term $\kappa \sqrt{\frac{2}{(N+1)}}\left(1-\hat{\rho}_{t}^{*}\right)$, which simply scales the standard deviation of $\hat{\rho}_{\mathrm{t}}$ by a factor $\kappa$, aims to avoid a systematic underestimation of the denominator in Eq. (18). For the $\kappa$ parameter Hartung suggests two alternative values: $\kappa_{1}=0.2$ and $\kappa_{2}=0.1 \cdot\left(1+\frac{1}{N-1}-\hat{\rho}_{t}^{*}\right)$, where $\kappa_{2}$ is suitable mainly for smaller $\hat{\rho}_{t}^{*}$.

The test statistic $t\left(\hat{\rho}_{t}^{*}, \kappa\right)$ has a $N(0,1)$ limiting distribution under the null hypothesis with a rejection region in the left tail.

\section{A.3 Auxiliary results}

See Figures 2, 3 and 4 and Tables 8, 9, 10, 11 and 12.

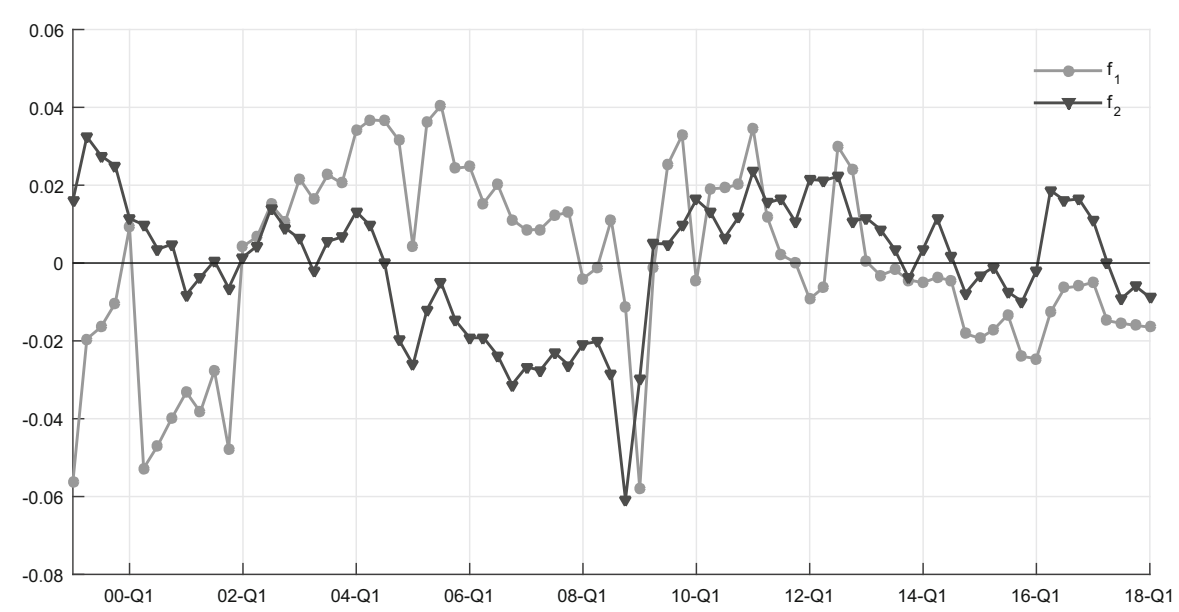

Fig. 2 Estimated common factors from the Cup-FM model

\footnotetext{
13 For simplicity the computation of the statistic is presented with unit weights for all cross sections, as in its current implementation.
} 

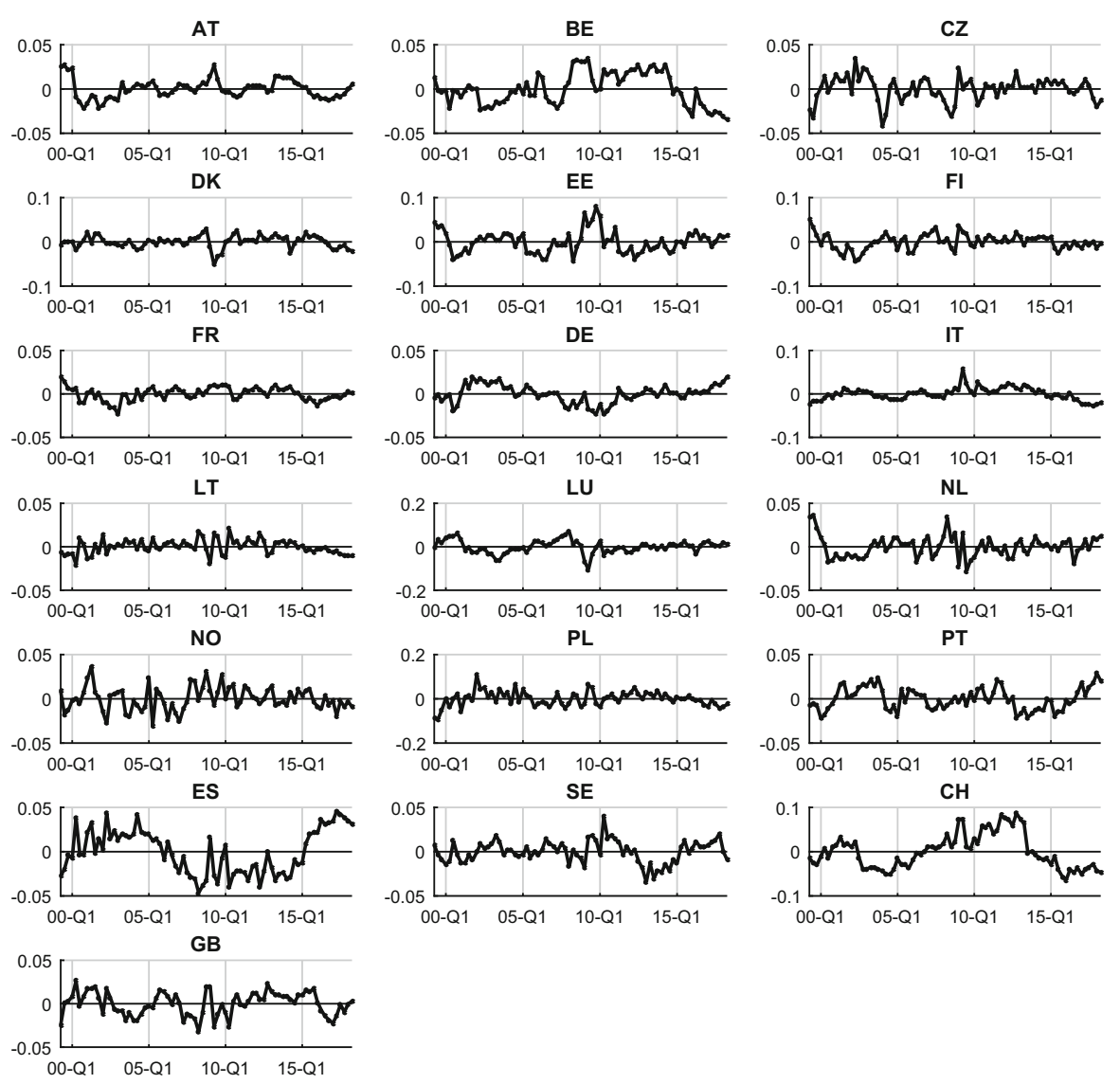

Fig. 3 Estimated residuals from the Cup-FM model 


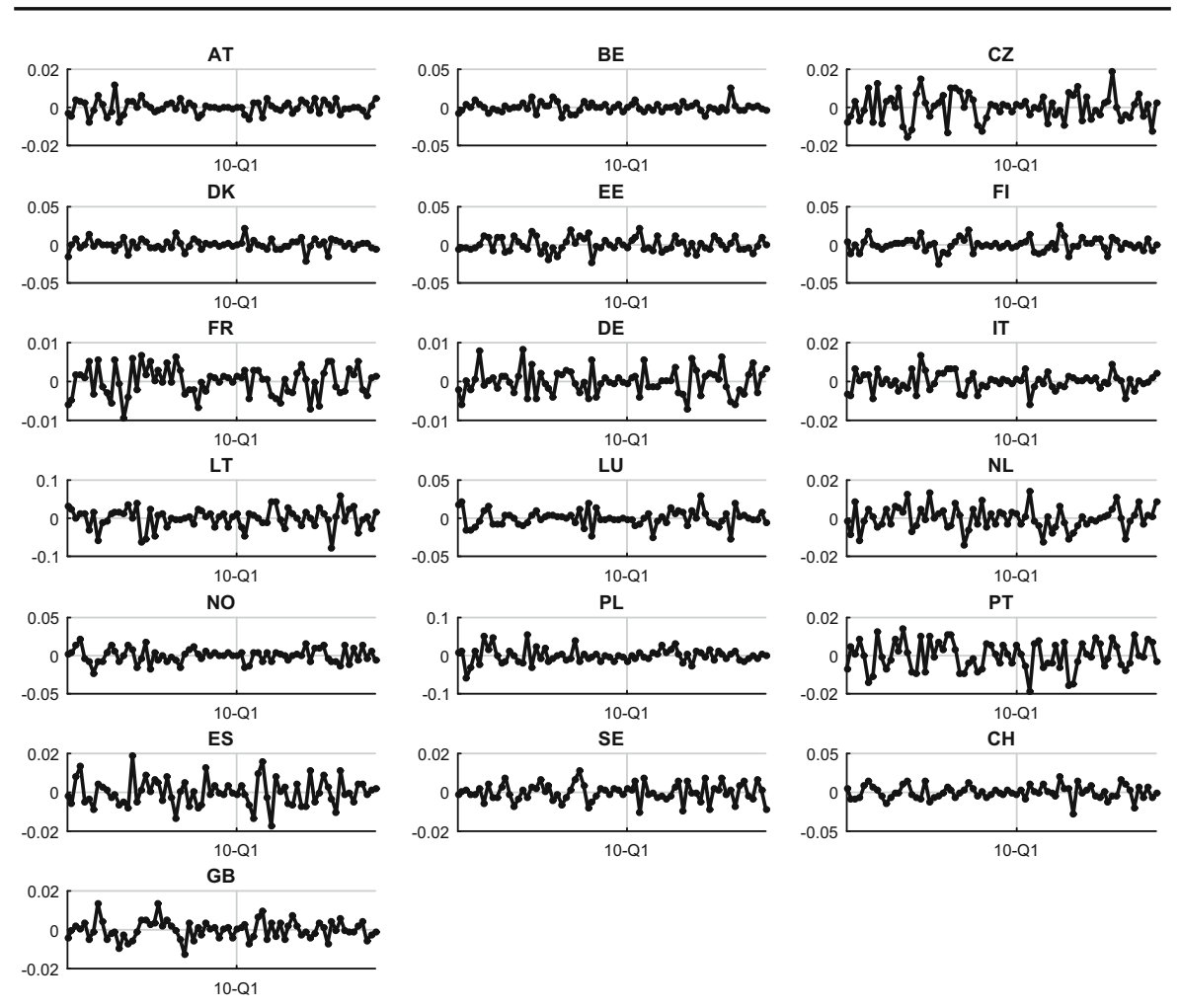

Fig. 4 Estimated residuals from the augmented DCCE model with trend 


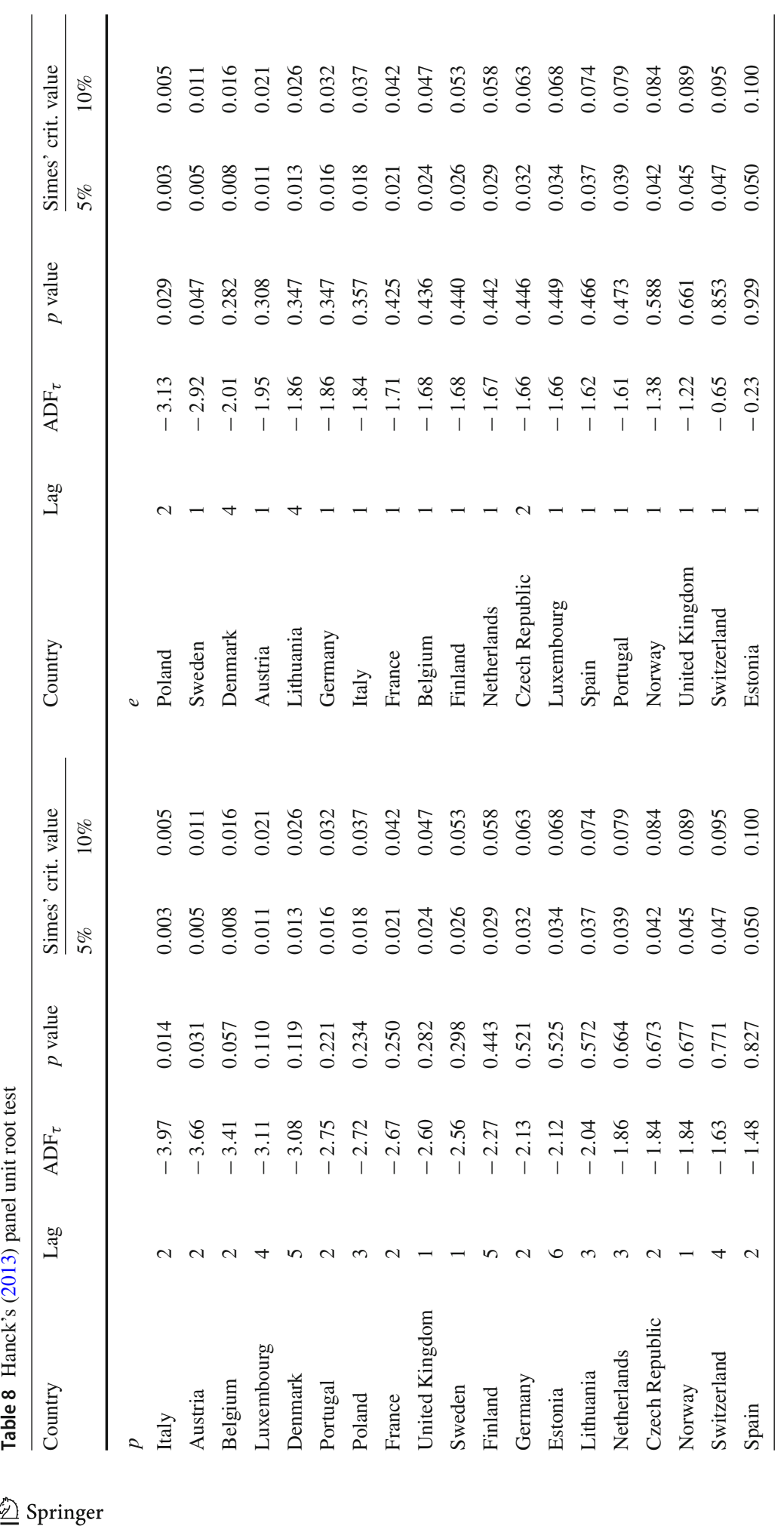




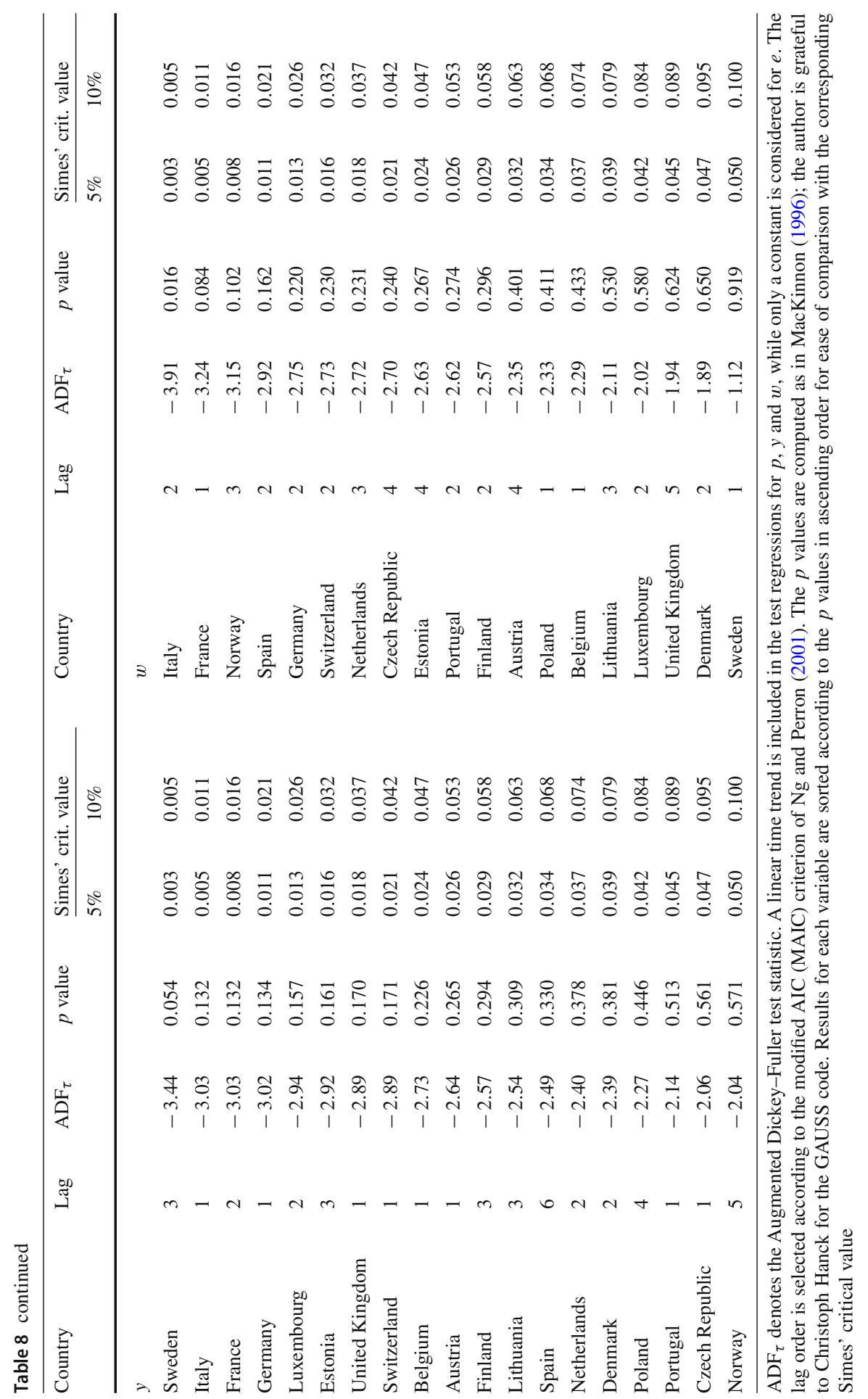


Table 9 Demetrescu et al.'s (2006) panel unit root test

\begin{tabular}{ll}
\hline Variable & Panel unit root test statistic \\
\hline$p$ & -0.804 \\
$e$ & -0.279 \\
$y$ & -0.719 \\
$w$ & -0.668
\end{tabular}

Demetrescu et al.'s (2006) test combines the individual ADF test $p$ values by the modified inverse normal method of Hartung (1999) with correction factor $\kappa_{1}=0.2$. Under the null hypothesis of a common unit root for all units it follows a $N(0,1)$ distribution

Table 10 Pesaran's (2007) CI PS panel unit root test

\begin{tabular}{lllllllll}
\hline Lag & $p$ & $e$ & $y$ & $w$ & $\Delta p$ & $\Delta e$ & $\Delta y$ & $\Delta w$ \\
\hline 6 & -2.037 & -1.662 & -2.322 & -1.548 & $-3.216^{* * *}$ & $-3.708^{* * *}$ & $-2.550^{* * *}$ & $-2.659^{* * *}$ \\
5 & -2.022 & -1.734 & -2.210 & -1.503 & $-3.378^{* * *}$ & $-4.134^{* * *}$ & $-2.807^{* * *}$ & $-3.071^{* * *}$ \\
4 & -2.049 & $-2.221^{* *}$ & -2.061 & -1.571 & $-3.971^{* * *}$ & $-4.442^{* * *}$ & $-3.084^{* * *}$ & $-3.751^{* * *}$ \\
3 & -2.218 & $-2.460^{* * *}$ & -2.267 & -1.851 & $-4.315^{* * *}$ & $-3.880^{* * *}$ & $-3.768^{* * *}$ & $-4.300^{* * *}$ \\
2 & -2.517 & $-2.305^{* *}$ & -2.116 & -2.050 & $-5.283^{* * *}$ & $-4.236^{* * *}$ & $-4.316^{* * *}$ & $-4.520^{* * *}$ \\
1 & $-2.702 * *$ & $-2.278^{* *}$ & -2.213 & -1.857 & $-5.798^{* * *}$ & $-5.200^{* * *}$ & $-5.168^{* * *}$ & $-5.196^{* * *}$
\end{tabular}

Trend is included in the test regressions for $p, y$ and $w$, while only a constant is considered for $e$. The $10 \%$, $5 \%$ and $1 \%$ critical values for the model with constant only are $-2.11,-2.2$ and -2.36 , and $-2.63,-2.7$ and -2.85 for the model with trend, respectively.

$*, * *$ and ${ }^{* * *}$ denote significance at the $10 \%, 5 \%$ and $1 \%$ level, respectively 
Table 11 Estimated factor loadings

\begin{tabular}{lcrrrrr}
\hline Country & $\hat{\Lambda}_{1}^{p}$ & \multicolumn{1}{c}{$\hat{\Lambda}_{2}^{p}$} & \multicolumn{1}{c}{$\hat{\Lambda}_{1}^{e}$} & $\hat{\Lambda}_{2}^{e}$ & $\hat{\Lambda}^{y}$ & $\hat{\Lambda}^{w}$ \\
\hline Austria & 1.19 & 0.57 & -1.26 & -0.13 & 1.14 & 1.76 \\
Belgium & 1.25 & -0.20 & -1.27 & -0.15 & 1.13 & 1.47 \\
Czech Republic & 1.06 & 0.23 & -0.46 & -1.71 & 1.15 & 0.17 \\
Denmark & 0.71 & -1.87 & -1.23 & 0.49 & 0.81 & 1.20 \\
Estonia & 0.94 & -0.90 & -0.83 & 1.52 & 0.95 & 0.84 \\
Finland & 1.08 & -0.18 & -1.25 & 0.25 & 1.11 & -0.32 \\
France & 1.37 & -0.08 & -1.27 & -0.28 & 1.22 & 1.36 \\
Germany & 1.35 & -0.26 & -1.27 & -0.17 & 1.11 & 0.35 \\
Italy & 1.32 & -0.04 & -1.27 & -0.20 & 1.23 & 0.57 \\
Lithuania & 0.56 & 1.78 & -0.15 & 1.32 & 0.93 & -0.06 \\
Luxembourg & 0.09 & -2.32 & -1.26 & 0.17 & 0.64 & 0.84 \\
Netherlands & 0.88 & 0.72 & -1.27 & -0.01 & 1.16 & 1.12 \\
Norway & 0.80 & -0.14 & -0.22 & -1.52 & 0.38 & 1.11 \\
Poland & 0.30 & 1.60 & -0.09 & -2.05 & 0.36 & 0.38 \\
Portugal & 1.20 & -0.79 & -1.27 & -0.06 & 0.94 & 1.09 \\
Spain & 1.24 & -0.41 & -1.27 & -0.07 & 1.06 & 0.96 \\
Sweden & 0.98 & 0.72 & -0.25 & -1.90 & 1.03 & -0.72 \\
Switzerland & 0.62 & 0.70 & 0.22 & 0.50 & 1.06 & 1.68 \\
United Kingdom & 0.86 & 0.84 & 0.60 & -1.07 & 1.01 & 0.63 \\
\hline
\end{tabular}

Estimated loadings for the common factors extracted from the panel for each variable with country cross sections. The superscript signifies the variable-specific panel and the subscript denotes the factor number 


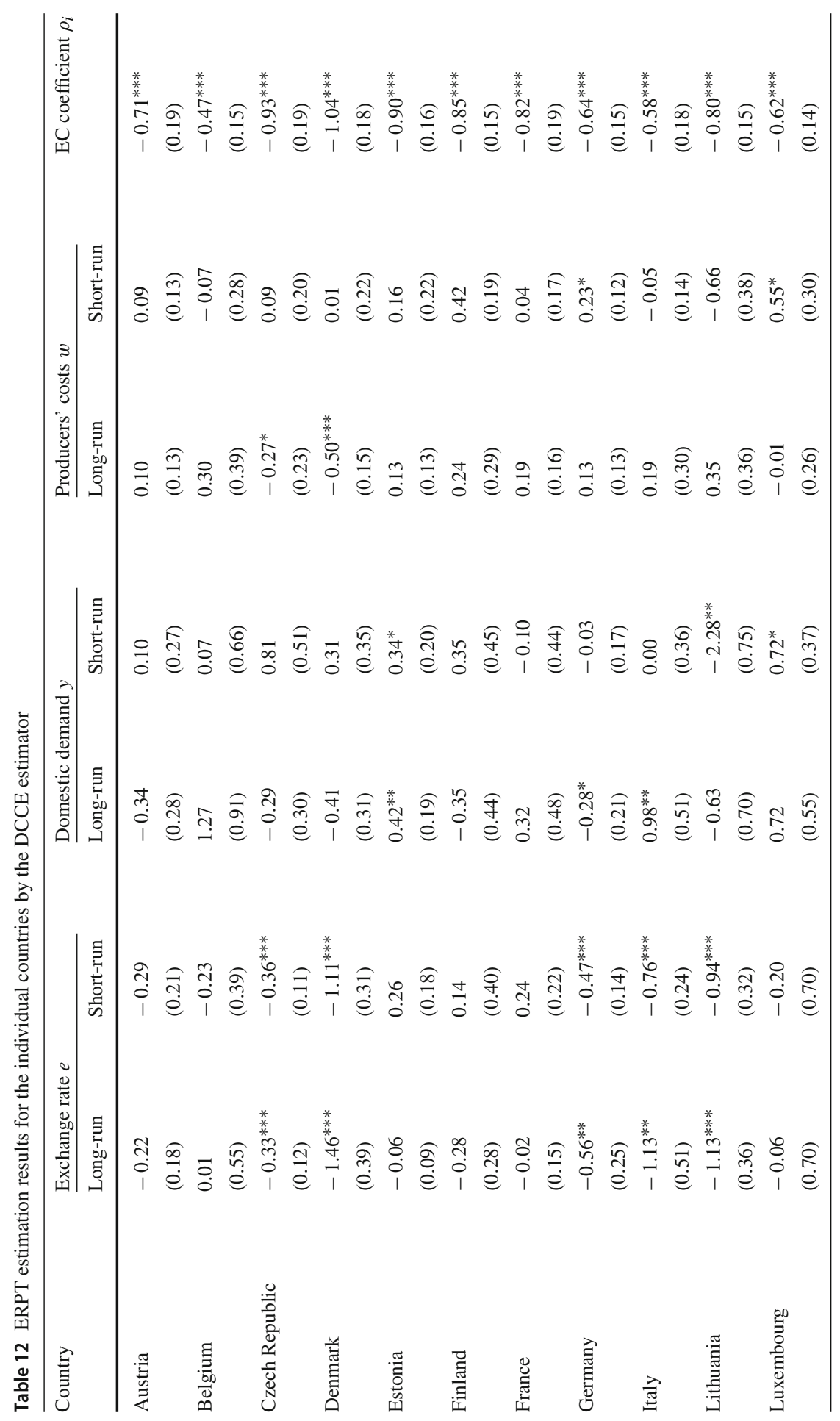




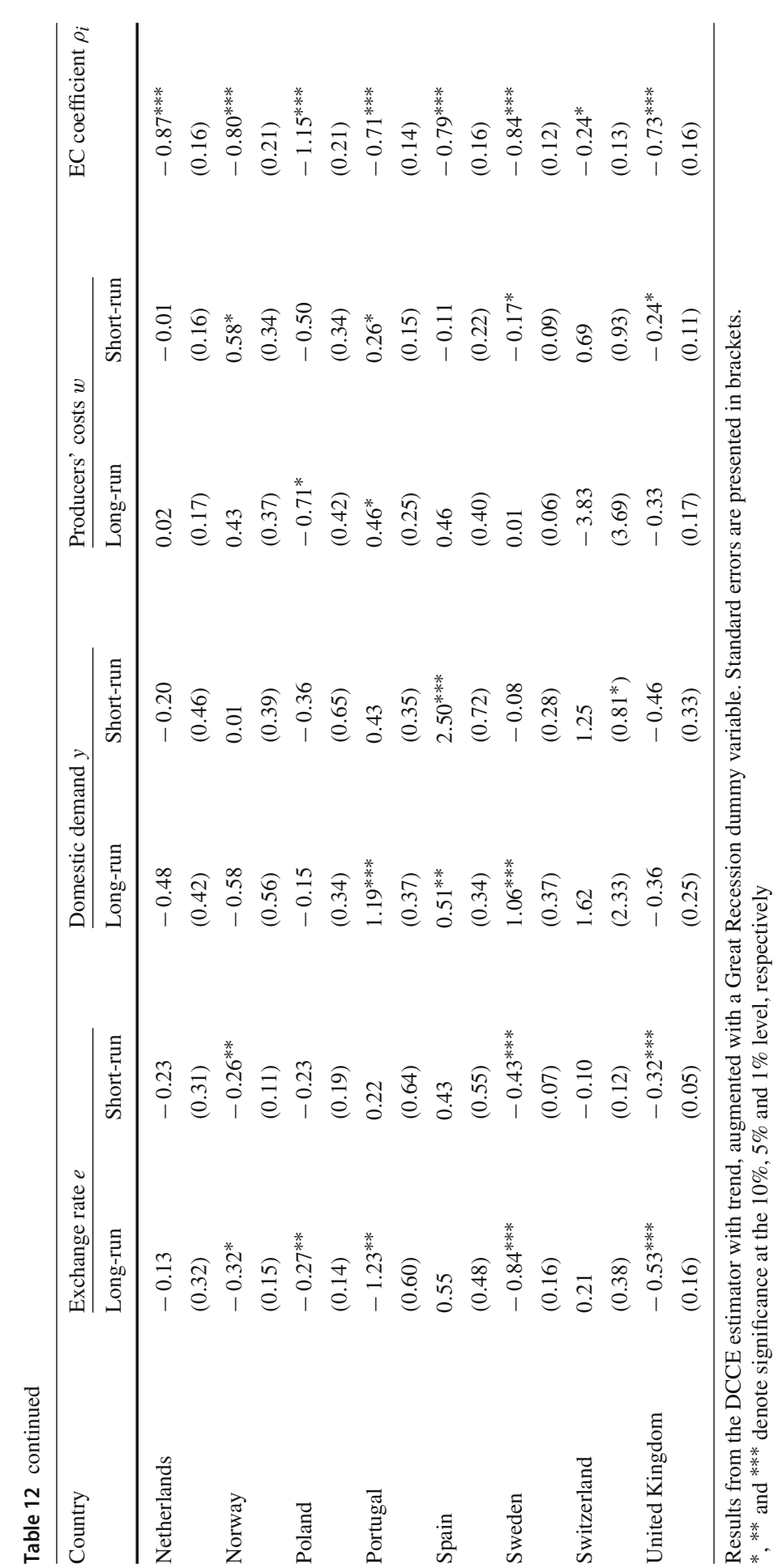




\section{A.4 Robustness check}

Oil price data (crude oil prices: Brent-Europe, dollars per barrel, monthly, not seasonally adjusted) has been obtained from the FRED Economic Data database of the Federal Reserve Bank of St. Louis. Quarterly observations are computed as the 3month average of the monthly observations in the corresponding quarter. The natural logarithm of the quarterly series is found to be $I(1)$ by the ADF test ( $t$-statistics -1.97 and -1.68 with $p$ values 0.298 and 0.751 in the constant and trend cases, respectively) (Tables 13, 14, 15). 


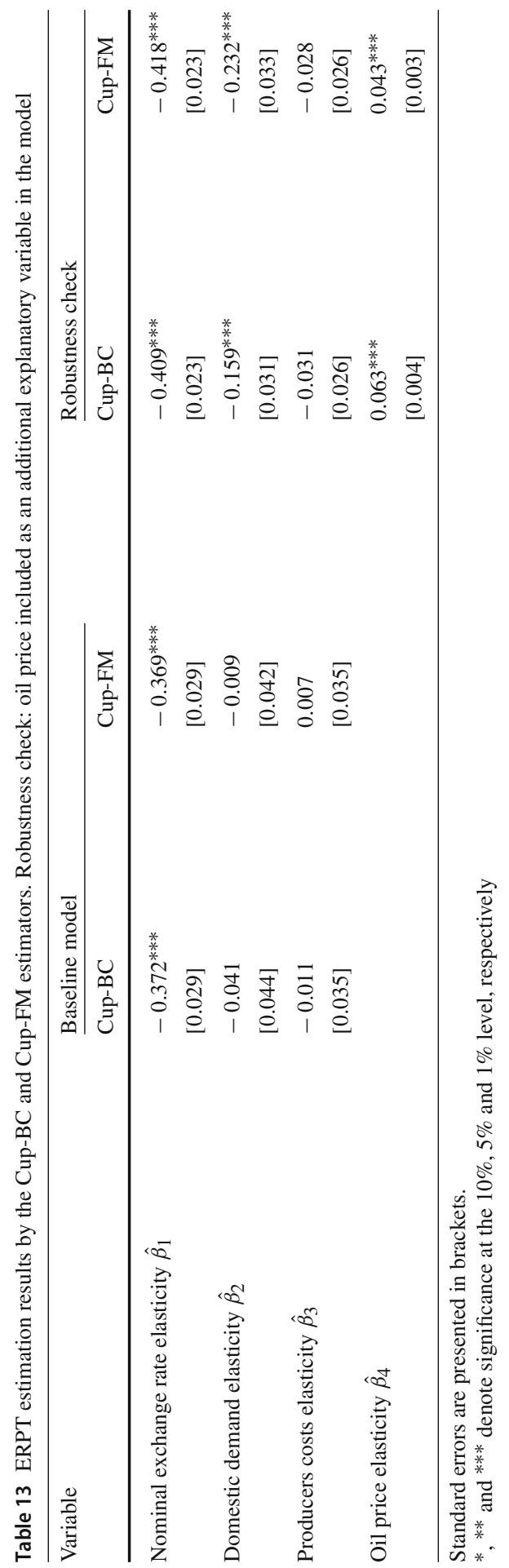


Table 14 ERPT estimation results by the CCE MG estimator. Robustness check: oil price included as an additional explanatory variable in the model

\begin{tabular}{|c|c|c|c|}
\hline \multicolumn{4}{|c|}{ Augmented DCCE estimator, trend } \\
\hline Variable & & Baseline model & Robustness check \\
\hline \multirow[t]{6}{*}{$e$} & \multirow[t]{2}{*}{ LRA } & $-0.343^{* * *}$ & $-0.365^{* * *}$ \\
\hline & & {$[0.118]$} & {$[0.127]$} \\
\hline & \multirow[t]{2}{*}{ ALR } & $-0.356^{* *}$ & $-0.356^{* * *}$ \\
\hline & & {$[0.138]$} & {$[0.138]$} \\
\hline & \multirow[t]{2}{*}{ SRA } & $-0.217^{* *}$ & $-0.257^{* * *}$ \\
\hline & & {$[0.100]$} & {$[0.094]$} \\
\hline \multirow[t]{6}{*}{$y$} & \multirow[t]{2}{*}{ LRA } & 0.086 & 0.235 \\
\hline & & {$[0.158]$} & {$[0.165]$} \\
\hline & \multirow[t]{2}{*}{ ALR } & 0.181 & 0.181 \\
\hline & & {$[0.194]$} & {$[0.194]$} \\
\hline & \multirow[t]{2}{*}{ SRA } & 0.148 & $0.228^{*}$ \\
\hline & & {$[0.107]$} & {$[0.125]$} \\
\hline \multirow[t]{6}{*}{$w$} & \multirow[t]{2}{*}{ LRA } & $0.134^{* *}$ & 0.123 \\
\hline & & {$[0.069]$} & {$[0.082]$} \\
\hline & \multirow[t]{2}{*}{ ALR } & 0.114 & 0.114 \\
\hline & & {$[0.079]$} & {$[0.079]$} \\
\hline & \multirow[t]{2}{*}{ SRA } & 0.074 & 0.086 \\
\hline & & {$[0.084]$} & {$[0.063]$} \\
\hline \multirow[t]{6}{*}{ Oil price } & \multirow[t]{2}{*}{ LRA } & & 0.002 \\
\hline & & & {$[0.007]$} \\
\hline & \multirow[t]{2}{*}{ ALR } & & 0.003 \\
\hline & & & {$[0.009]$} \\
\hline & \multirow[t]{2}{*}{ SRA } & & $-0.008^{*}$ \\
\hline & & & {$[0.005]$} \\
\hline \multicolumn{2}{|l|}{ EC coefficient $\rho$} & $-0.783^{* * *}$ & $-0.833^{* * *}$ \\
\hline \multicolumn{2}{|l|}{ St. Error } & {$[0.042]$} & {$[0.062]$} \\
\hline \multicolumn{2}{|l|}{ Implied half-life (quarters) } & 0.45 & 0.39 \\
\hline \multicolumn{2}{|l|}{ RMSE } & 0.009 & 0.008 \\
\hline \multicolumn{2}{|l|}{ CD test } & 0.51 & 0.68 \\
\hline \multicolumn{2}{|l|}{ Trends share } & 0.21 & 0.32 \\
\hline
\end{tabular}

Augmented DCCE estimator denotes the DCCE estimator augmented with a dummy variable accounting for the Great Recession in 2008. LRA and SRA denote long-run and short-run average coefficients, respectively, computed by first averaging the estimated coefficients of the individual EC models (15) and then computing the long-run (short-run) parameters. ALR denotes the average long-run coefficient, whereas the long-run coefficients are computed for each country first and then averaged across the panel. Outlier-robust means are employed for averaging in both cases. Standard errors are presented in brackets. Standard errors for the LRA estimates are computed by the Delta method. Implied half-life is computed as $\ln (0.5) / \ln (1+\bar{\rho})$. CD test denotes Pesaran's (2015) test for weak cross-sectional dependence of the regression residuals; it follows a $N(0,1)$ distribution under the null hypothesis. Trends share stands for the share of group-specific trends significant at the $5 \%$ level.

$*,{ }^{* *}$ and ${ }^{* * *}$ denote significance at the $10 \%, 5 \%$ and $1 \%$ level, respectively 


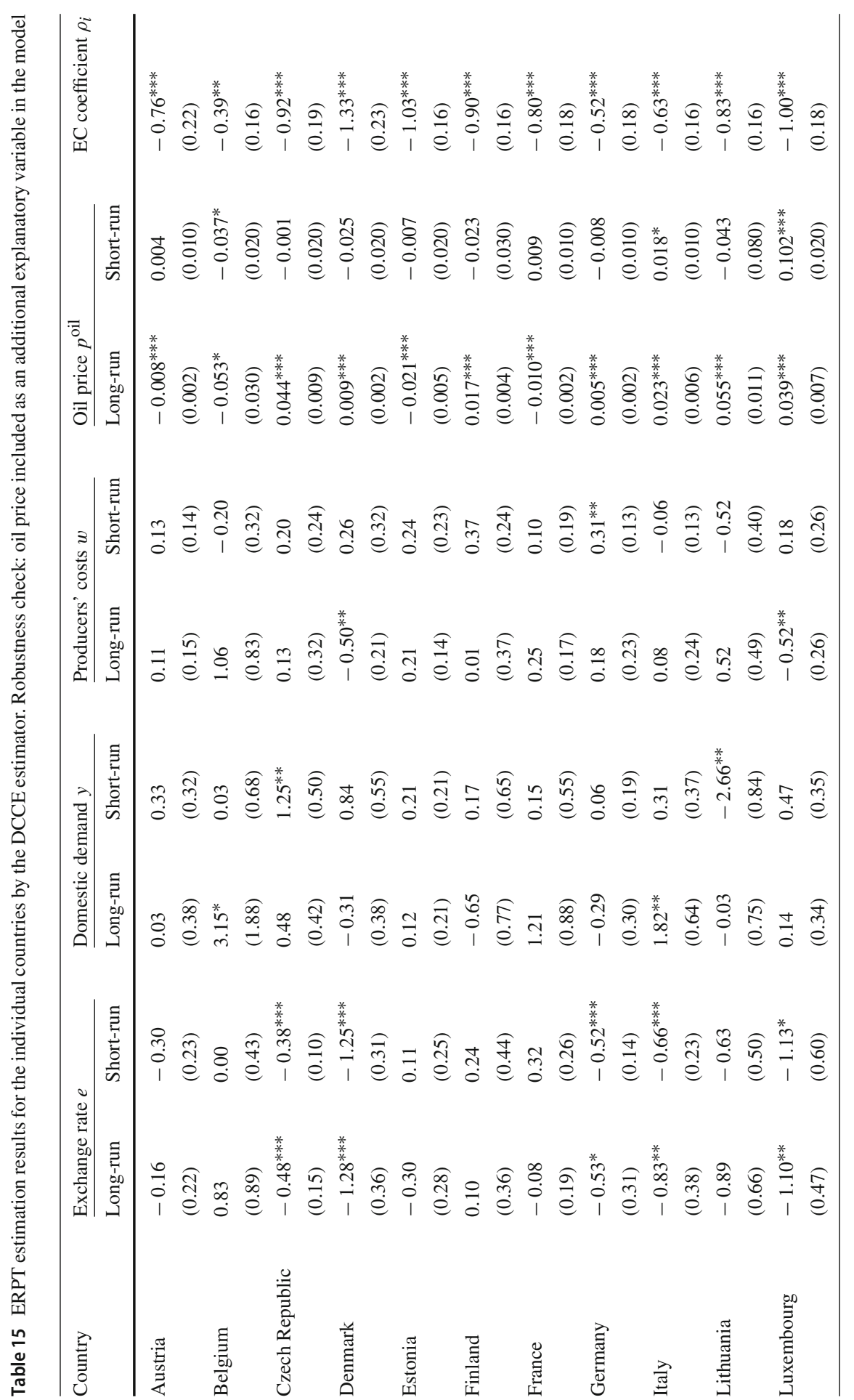




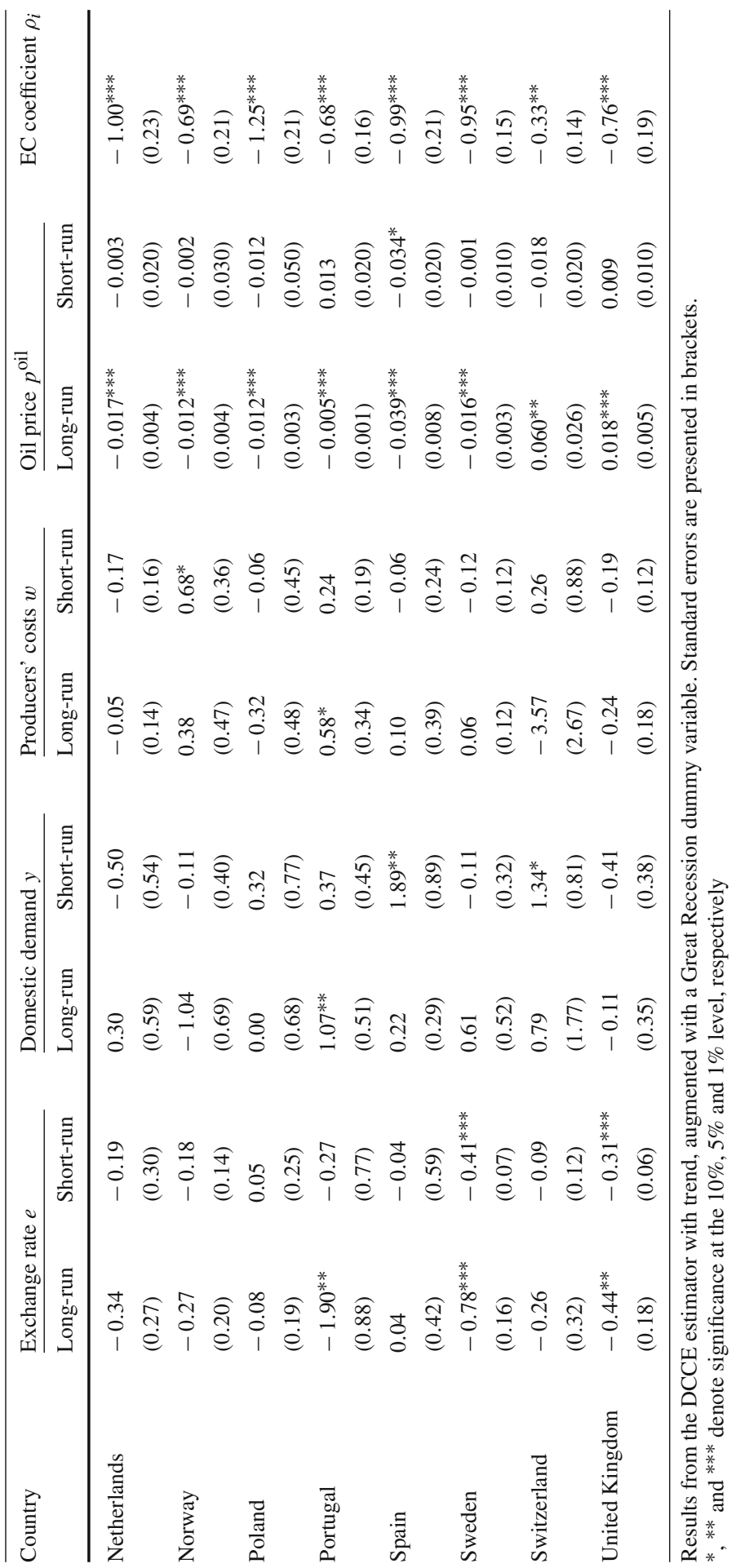




\section{References}

Arsova A, Örsal DDK (2018) Likelihood-based panel cointegration test in the presence of a linear time trend and cross-sectional dependence. Econom Rev 37:1033-1050

Arsova A, Örsal DDK (2020) Intersection tests for the cointegrating rank in dependent panel data. Commun Stat Simul Comput 49(4):918-941

Bai J, Ng S (2004) A PANIC attack on unit roots and cointegration. Econometrica 72:1127-1177

Bai J, Ng S (2010) Panel unit root tests with cross-section dependence: a further investigation. Econom Theory 26:1088-1114

Bai J, Kao C, Ng S (2009) Panel cointegration with global stochastic trends. J Econom 149:82-99

Bailliu J, Fujii E (2004) Exchange rate pass-through and the inflation environment in industrialized countries: an empirical investigation. Working paper 2004-21. Bank of Canada

Banerjee A, Marcellino M, Osbat C (2004) Some cautions on the use of panel methods for integrated series of macroeconomic data. Econom J 7:322-340

Beirne J, Bijsterbosch M (2009) Exchange rate pass through in Central and Eastern European member states. Working paper 1120. European Central Bank

Ben Cheikh N, Cheik HM (2013) A panel cointegration analysis of the exchange rate pass-through. Econ Bull 33:2278-2790

Ben Cheikh N, Louhichi W (2016) Revisiting the role of inflation environment in exchange rate passthrough: a panel threshold approach. Econ Model 52:A:233-238

Ben Cheikh N, Rault C (2016) Recent estimates of exchange rate pass-through to import prices in the euro area. Rev World Econ 152:69-105

Ben Cheikh N, Rault C (2017) Investigating first-stage exchange rate pass-through: sectoral and macro evidence from euro area countries. World Econ 40:2611-2638

Blagov B (2020) Exchange rate uncertainty and import prices in the euro area. Rev Int Econ 27(5):15371572

Bodart V, Candelon B, Carpantier JF (2015) Real exchanges rates, commodity prices and structural factors in developing countries. J Int Money Finance 51:264-284

Brun-Aguerre R, Fuertes AM, Phylaktis K (2012) Exchange rate pass-through into import prices revisited: what drives it? J Int Money Finance 31:818-844

Brun-Aguerre R, Fuertes AM, Greenwood-Nimmo M (2017) Heads I win; tails you lose: asymmetry in exchange rate pass-through into import prices. J R Stat Soc Ser A (Stat Soc) 180:587-612

Bussiere M (2013) Exchange rate pass-through to trade prices: the role of nonlinearities and asymmetries. Oxf Bull Econ Stat 75:731-758

Campa JM, Goldberg LS (2005) Exchange rate pass-through into import prices. Rev Econ Stat 87:679-690

Cheng L, Sheng X (2017) Combination of “combinations of p-values". Empir Econ 53:329-350

Chudik A, Pesaran MH (2015) Common correlated effects estimation of heterogeneous dynamic panel data models with weakly exogenous regressors. J Econom 188:393-420

Chudik A, Pesaran MH, Tosetti E (2011) Weak and strong cross-section dependence and estimation of large panels. Econom J 14:C45-C90

Colavecchio R, Rubene I (2020) Non-linear exchange rate pass-through to euro area inflation: a local projection approach. Working paper 2362. European Central Bank

Comunale M, Kunovac D (2017) Exchange rate pass-through in the euro area. Working paper 2003. European Central Bank

De Bandt O, Razafindrabe T (2014) Exchange rate pass-through to import prices in the euro-area: a multicurrency investigation. Int Econ 138:63-77

De Bandt O, Banerjee A, Kozluk T (2008) Measuring long-run exchange rate pass-through. Econ Open Access Open Assess E J 2:1

Delatte AL, López-Villavicencio A (2012) Asymmetric exchange rate pass-through: evidence from major countries. J Macroecon 34:833-844

Demetrescu M, Hassler U, Tarcolea AI (2006) Combining significance of correlated statistics with application to panel data. Oxf Bull Econ Stat 68:647-663

Eberhardt M, Presbitero AF (2015) Public debt and growth: heterogeneity and non-linearity. J Int Econ 97:45-58

Forbes K, Hjortsoe I, Nenova T (2018) The shocks matter: improving our estimates of exchange rate pass-through. J Int Econ 114:255-275

Hanck C (2013) An intersection test for panel unit roots. Econom Rev 32:183-203 
Hartung J (1999) A note on combining dependent tests of significance. Biom J 41:849-855

Hommel G (1988) A stagewise rejective multiple test procedure based on a modified Bonferroni test. Biometrika 75:383-386

Kapetanios G, Pesaran MH, Yamagata T (2011) Panels with non-stationary multifactor error structures. J Econom 160:326-348

MacKinnon JG (1996) Numerical distribution functions for unit root and cointegration tests. J Appl Econom 11:601-618

Moon HR, Weidner M (2017) Dynamic linear panel regression models with interactive fixed effects. Econom Theory 33:158-195

$\mathrm{Ng} \mathrm{S}$, Perron P (2001) LAG length selection and the construction of unit root tests with good size and power. Econometrica 69:1519-1554

Onatski A (2010) Determining the number of factors from empirical distribution of eigenvalues. Rev Econ Stat 92:1004-1016

Örsal DDK (2017) Analysing money demand relation for OECD countries using common factors. Appl Econ 49:6003-6013

Örsal DDK, Arsova A (2017) Meta-analytic cointegrating rank tests for dependent panels. Econom Stat 2:61-72

Pesaran MH(2006) Estimation and inference in large heterogeneous panels with a multifactor error structure. Econometrica 74:967-1012

Pesaran MH (2007) A simple panel unit root test in the presence of cross-section dependence. J Appl Econom 22:265-312

Pesaran MH (2015) Testing weak cross-sectional dependence in large panels. Econom Rev 34:1089-1117

Pesaran M, Smith R (1995) Estimating long-run relationships from dynamic heterogeneous panels. J Econom 68:79-113

Phillips PCB, Sul D (2003) Dynamic panel estimation and homogeneity testing under cross section dependence. Econom J 6:217-259

Phillips PC, Sul D (2007) Bias in dynamic panel estimation with fixed effects, incidental trends and cross section dependence. J Econom 137:162-188

Przystupa J, Wrobel E (2011) Asymmetry of the exchange rate pass-through: an exercise on Polish data. East Eur Econ 49:30-51

Qu Z, Perron P (2007) A modified information criterion for cointegration tests based on a VAR approximation. Econom Theory 23:638-685

Saikkonen P, Lutkepohl H (2000) Trend adjustment prior to testing for the cointegrating rank of a vector autoregressive process. J Time Ser Anal 21:435-456

Sheng X, Yang J (2012) Truncated product methods for panel unit root tests. Oxf Bull Econ Stat 75:624-636

Shin Y, Yu B, Greenwood-Nimmo MJ (2014) Modelling asymmetric cointegration and dynamic multipliers in a nonlinear ARDL framework. In: Sickles RC, Horrace WC (eds) Festschrift in honor of Peter Schmidt: econometric methods and applications. Springer, New York

Simes RJ (1986) An improved Bonferroni procedure for multiple tests of significance. Biometrika 73:751

Smeekes S, Urbain J (2014) On the applicability of the sieve bootstrap in time series panels. Oxf Bull Econ Stat 76:139-151

Urbain JP, Westerlund J (2006) Spurious regression in nonstationary panels with cross-unit cointegration. Working paper RM/06/057. Universiteit Maastricht

Westerlund J (2007) Testing for error correction in panel data. Oxf Bull Econ Stat 69:709-748

Publisher's Note Springer Nature remains neutral with regard to jurisdictional claims in published maps and institutional affiliations. 